NBER WORKING PAPER SERIES

\title{
DOES KNOWING YOUR FICO SCORE CHANGE FINANCIAL BEHAVIOR? EVIDENCE FROM A FIELD EXPERIMENT WITH STUDENT LOAN BORROWERS
}

\author{
Tatiana Homonoff \\ Rourke O'Brien \\ Abigail B. Sussman \\ Working Paper 26048 \\ http://www.nber.org/papers/w26048 \\ NATIONAL BUREAU OF ECONOMIC RESEARCH \\ 1050 Massachusetts Avenue \\ Cambridge, MA 02138 \\ July 2019
}

We gratefully acknowledge Marianne Bertrand, Anat Bracha, Michael Collins, Jacob Goldin, Sam Hartzmark, Emir Kamenica, Neale Mahoney, Sanjog Misra, Devin Pope, Justin Sydnor, Oleg Urminsky, George Wu, and participants in seminars at NYU, Rutgers, USC, USMA-West Point, Washington University in St. Louis, Wharton, Wisconsin, Yale, the Federal Reserve Bank of New York and in the Chicago Booth Behavioral Approaches to Financial Decision-Making Conference, Cornell IBHF Conference, Boulder Summer Conference on Consumer Financial Decision Making, the CFPB Research Conference and the Advances in Field Experiments Conference for conversations and suggestions that have greatly improved the quality of this project. We also thank Jennifer Chellew, Monica Milone, Ryan Corey, Annat Shrabstein, and Marie O'Malley from Sallie Mae as well as Joanne Gaskin and Jenelle Dito from FICO for their assistance throughout the project. Nicholas Herzog provided excellent research assistance. All remaining errors are our own. This work was supported by the True North Communications Inc. Faculty Research Funds at The University of Chicago Booth School of Business. The views expressed herein are those of the authors and do not necessarily reflect the views of the National Bureau of Economic Research.

NBER working papers are circulated for discussion and comment purposes. They have not been peer-reviewed or been subject to the review by the NBER Board of Directors that accompanies official NBER publications.

(C) 2019 by Tatiana Homonoff, Rourke O'Brien, and Abigail B. Sussman. All rights reserved. Short sections of text, not to exceed two paragraphs, may be quoted without explicit permission provided that full credit, including $\odot$ notice, is given to the source. 
Does Knowing Your FICO Score Change Financial Behavior? Evidence from a Field Experiment with Student Loan Borrowers Tatiana Homonoff, Rourke O'Brien, and Abigail B. Sussman NBER Working Paper No. 26048

July 2019

JEL No. D14

\begin{abstract}
One in five consumer credit accounts incur late fees each quarter. Evidence on the efficacy of regulations to improve behavior through enhanced disclosure of financial product attributes is mixed. We test a novel form of disclosure that provides borrowers with a personalized measure of their creditworthiness. In a field experiment with over 400,000 student loan borrowers, treatment group members received communications about the availability of their FICO Score. The intervention significantly reduced late payments and increased borrowers' FICO Scores. Survey data show treatment group members were less likely to overestimate their FICO Scores, suggesting the intervention may correct for overoptimism.

Tatiana Homonoff

New York University

Robert F. Wagner School of Public Service

295 Lafayette Street, 2nd Floor

New York, NY 10012

and NBER

tatiana.homonoff@nyu.edu

Rourke O'Brien

Yale University

Department of Sociology

493 College Street

New Haven, CT 06511

Rourke.obrien@yale.edu

Abigail B. Sussman

University of Chicago

Booth School of Business

5807 South Woodlawn Avenue

Chicago, IL 60637

abigail.sussman@chicagobooth.edu
\end{abstract}

A randomized controlled trials registry entry is available at AEARCTR-0002871 
Consumers struggle when making financial decisions. These difficulties often translate to costly mistakes across several domains of household finance, from investment and retirement savings decisions to mortgage choice and debt management (Benartzi and Thaler, 2001; Choi et al., 2009; Gross and Souleles, 2002; Ponce, Seira and Zamarripa, 2017). In the context of consumer credit, one common and costly behavior is failing to make minimum payments on time. Past-due accounts can lead to a variety of downstream consequences such as penalty fees, higher interest rates, and lower credit scores. ${ }^{1}$ Recent estimates indicate that approximately 20 percent of consumer credit accounts incur late fees each quarter (CFPB, 2015 ), amounting to more than $\$ 11$ billion per year in penalty fees for late payments. ${ }^{2}$

Given the direct implications for consumer welfare, improving financial decision-making has become a focus in recent decades with actors in the public, private, and nonprofit sectors implementing a wide range of interventions. Recent legislation has focused on improving consumer decisions by providing enhanced disclosures such as those mandated in the Credit Card Accountability Responsibility and Disclosure (CARD) Act of 2009 and in state regulation of payday lending. These disclosures typically aim to simplify information about financial products such as interest rates, repayment terms, or penalty fees.

Our intervention tests a novel form of disclosure that provides borrowers with information about themselves rather than about attributes of financial products. Specifically, we provide individuals with a personalized, quantifiable, and behaviorally-responsive measure of their creditworthiness: their FICO Score. We present evidence from a large-scale field experiment with over 400,000 clients of Sallie Mae, a national financial institution specializing in student loans. Beginning in June 2015, Sallie Mae offered borrowers access to unlimited views of their FICO Score. This was part of a broader initiative- the FICO Score Open Access Programto increase consumer access to their Scores through partnering financial institutions. As of 2018, more than 250 million consumer accounts included free access to FICO Scores.

\footnotetext{
${ }^{1}$ https://www.americanexpress.com/us/content/financial-education/how-late-payments-affect-yourcredit-score.html; $\quad$ https://www.discover.com/credit-cards/resources/what-happens-if-you-dont-pay-acredit-card

${ }^{2}$ https://www.wsj.com/articles/amex-raises-its-fee-for-late-payments-1480069802
} 
We exogenously vary the likelihood of viewing one's FICO Score page by randomly assigning borrowers to receive direct communications about the program's availability. To estimate the effect of the intervention on financial outcomes, we examine individual-level credit report data provided by TransUnion. Borrowers assigned to the treatment group received quarterly email messages notifying them that an updated FICO Score was available to view through Sallie Mae's website and provided instructions on how to view their Score. During the first year of the intervention, 32 percent of treatment group members viewed their personalized page at least once, an 8 percentage point increase over the control group.

We find that the intervention led to a significant decrease in the likelihood of having a late payment one year after the intervention. Specifically, treatment group members were 0.7 percentage points less likely to have an account that was 30 days or more past due, a 4 percent decrease relative to the control group. This change in payment behavior is quite large, especially given that less than half of treatment group members ever opened the email and an even smaller fraction ever logged in to view their score. The intervention also led to a net positive outcome for the borrower's creditworthiness as indicated by an increase in the borrower's FICO Score (a statistically significant increase of 0.7 points) and reduced the proportion of subprime borrowers by 0.4 percentage points. These effects largely persist across the full two year study period.

A key component of our intervention entails prompting individuals to view their personal FICO Score page, which is not included in the email message. This page includes the borrower's FICO Score along with two reason codes detailing key factors contributing to their Score. While the intent-to-treat estimates are the policy relevant estimates for financial institutions considering a similar email campaign, we also investigate the effect of viewing one's FICO Score on financial behaviors by using treatment status as an instrument for the likelihood of viewing one's FICO Score page. Our estimates suggest that borrowers who were induced to view their FICO Score page as a result of our intervention are 9.0 percentage points less likely to have a 30-day late payment, contributing to an 8.2 point increase in the 
FICO Score itself and a 5.1 percentage point decrease in the likelihood of being classified as a subprime borrower. For comparison, removal of a bankruptcy flag leads to a FICO Score increase in the range of 10 to 15 points (Dobbie et al., 2016; Gross, Notowidigdo and Wang, Forthcoming). While we cannot disentangle the effects of viewing one's Score separately from viewing the associated reason codes, we provide evidence that treatment effects are not driven solely by additional information provided in the reason codes.

We complement findings from this field experiment by analyzing responses to a survey conducted by Sallie Mae one year after the start of the intervention, completed by a small subset of our borrower population. The survey asked participants questions about their FICO Score knowledge and general financial literacy. We find that treatment group members were more likely to accurately report their FICO Score. Specifically, treatment group members were less likely to overestimate their FICO Scores. This is consistent with literature on overoptimism and overconfidence (Kahneman and Tversky, 1996; Fischhoff, Slovic and Lichtenstein, 1977; Svenson, 1981) and suggests the intervention may lead to behavior change in part by allowing people to properly calibrate their creditworthiness. In contrast, we find no differences in general financial literacy or the ability to identify actions associated with improving creditworthiness across experimental groups.

We test whether repeated email reminders are necessary to maintain the effects on financial outcomes we observe in the first year of the intervention by using a separate sample - our "discontinued sample" - who only received emails for the first three quarters of the intervention. We find no significant differences in financial outcomes between the main treatment group and the discontinued sample, evaluated a full year after the discontinued sample stopped receiving communications, suggesting no additional positive effect of repeated reminders on financial behavior. Additionally, we tested whether the content of the message impacted FICO Score views or financial outcomes by varying whether the quarterly email contained (1) instructions on how to view their Score; (2) instructions plus additional information about economic consequences of FICO Scores; or (3) instructions plus additional 
information about peer behavior. We saw no differences as a function of the specific message received.

Our intervention design builds on several promising strategies that focus on improving financial outcomes. One strategy aims to improve decision-making through enhanced disclosures. In the context of payday lending, Bertrand and Morse (2011) found that disclosures clarifying interest costs reduced borrowing. Motivated by these insights, recent legislation such as the CARD Act and the Truth-in-Lending Act (TILA)-mandate the use of enhanced disclosures for a range of financial products. However, research suggests that complexity or confusion over the information provided in these disclosures inhibits their efficacy (Carpenter et al., 2017). For example, Lacko and Pappalardo (2010) find that mortgage cost disclosures required by TILA are ineffective, with many consumers misunderstanding key terms. Similarly, Seira, Elizondo and Laguna-Muggenburg (2017) find no evidence that TILA-type information disclosures change consumer behavior. Agarwal et al. (2014) find that the CARD Act's 36-month disclosure requirement led to minimal changes in payment behavior overall. ${ }^{3}$ This is consistent with findings on the role of simplification of information in improving consumer choice in the context of medicare prescription drug plans (Kling et al., 2012) and EITC take-up (Bhargava and Manoli, 2015).

Reminders have also been shown to help people accomplish desired actions such as building savings or repaying debt (Cadena and Schoar, 2011; Karlan et al., 2016; Bracha and Meier, 2019). Consistent with an account of limited attention (Bordalo, Gennaioli and Shleifer, 2013; Chetty, Looney and Kroft, 2009; Malmendier and Lee, 2011), reminders operate by making previously known information salient at the right moment. In two very different contexts, Bracha and Meier (2019) and Cadena and Schoar (2011) find evidence that reminding individuals to pay their bills on time leads to reductions in delinquencies and positive financial outcomes. ${ }^{4}$ Karlan et al. (2016) focus on a different financial behavior,

\footnotetext{
${ }^{3}$ This component of the CARD Act required lenders to state the amount consumers would need to pay each month to repay their bill in full in three years. Notably, changes that were observed were primarily driven by an increase in the share of accounts paying exactly the 36-month amount.

${ }^{4}$ The positive effects observed in Bracha and Meier (2019) are limited to individuals with the lowest
} 
personal savings, and also find positive effects of reminder messages.

A related literature suggests that correcting for an existing bias or other cognitive limitation may improve financial decision-making. For example, people are often overly confident about their own knowledge and ability (Kahneman and Tversky, 1996; Fischhoff, Slovic and Lichtenstein, 1977; Svenson, 1981). This has consequences in a variety of domains. ${ }^{5}$ In the context of creditworthiness, Perry (2008) finds that more than 30 percent of people overestimate their credit scores, suggesting that overoptimism could contribute to poor financial decision-making. This miscalibration of one's own creditworthiness may have direct consequences for consumer financial outcomes.

One common thread across these distinct approaches to improving outcomes for consumers is the efficacy of strategies that include personalized information. For example, Seira, Elizondo and Laguna-Muggenburg (2017) find that among the range of disclosures considered, the only message that influenced credit behavior was a warning that highlighted borrowers' low credit scores. Similarly, the most effective reminder message in Karlan et al. (2016) included information on the individual's personal savings goals. This is consistent with prior research showing that individuals are responsive to negative feedback about their financial behaviors. For example, Agarwal et al. (2008) find individuals who incur credit card fees take steps that serve to reduce fees incurred over time. Moreover, Bracha and Meier (2019) show that providing individuals with delayed - and therefore potentially inaccurate - information about their creditworthiness may have unintended consequences.

By providing individuals with quarterly messages to view their current FICO Score, our intervention incorporates several of the promising elements from these literatures: reminders, clearly communicated information, and personalized feedback. Our intervention also highlights the promise of interventions designed to correct for cognitive biases.

baseline credit scores. This intervention also included reminders about creditworthiness and the consequences of low credit scores.

${ }^{5}$ For example, Biais et al. (2005) show that overconfident traders are more likely to demonstrate the winner's curse, and Camerer and Lovallo (1999) show that overestimating chances of success in a new venture can lead to increased market entry and financial loss. 
The paper is structured as follows. Section I provides background on FICO Scores and the Open Access initiative. Section II presents an overview of the field experiment. Section III provides a description of our data. Section IV presents findings on the effect of the intervention on viewing behavior and financial outcomes. Section V discusses mechanisms. Section VI concludes.

\section{Background on FICO Scores and Open Access Initiative}

FICO Scores, a product of the Fair Isaac Corporation, are commonly used by financial institutions to make consumer credit decisions. FICO Scores are calculated using information collected by the major credit bureaus and are constructed using a proprietary algorithm that incorporates information about an individual's outstanding debt, payment history, length of credit usage, mix of credit used, and applications for new credit (see Appendix Figure A.1). Although the FICO Score is traditionally used to assess creditworthiness by lenders, the Score has become increasingly utilized outside of the financial services sector (Bartik and Nelson, 2016; Clifford and Shoag, 2016; Dobbie et al., 2016).

In recent years there has been a push by policymakers, regulators and financial service providers to increase consumer access to their credit information, including credit reports and credit scores. In November 2013, FICO joined this effort by launching the FICO Score Open Access Program. Through this initiative, institutions that purchase FICO Scores for use in risk management make those Scores available directly to the consumer. All financial institutions that participated in the program made FICO Scores available to their customers free of charge via a password protected website. Alongside the FICO Score itself, institutions were required to include two "reason codes" that explain the key factors contributing to the individual's Score, such as limited credit history or account delinquency. As of January 2018, FICO had partnered with 8 of the top 10 credit card issuers and more than 100 financial institutions including Bank of America, Wells Fargo, Chase and Citi, to provide free access 
to more than 250 million consumer credit and loan accounts in the US. ${ }^{6}$

\section{Experiment Overview}

On June 24, 2015, Sallie Mae, a national financial institution specializing in student loans, joined the FICO Score Open Access Program and began providing free Score access to customers through their website. Consistent with requirements of the Open Access Program, clients who logged in to the website saw a visual display that included their FICO Score beside a barometer showing the range of possible FICO Scores and two reason codes (Figure 1).

While all customers had the ability to $\log$ in and view this information, many borrowers may not have been aware of the new program. To test the effect of providing information about a borrower's FICO Score, we experimentally vary knowledge of FICO Score availability through additional communication about the program across the 406,994 student loan borrowers who held a loan with Sallie Mae at the start of the FICO Score Open Access program and continued to hold that loan for the following two years.

\section{A. Experimental Conditions}

Prior to the roll-out of the FICO Score Open Access Program at Sallie Mae, borrowers were randomly assigned to one of four experimental groups - three treatment groups and one control group. Roughly 90 percent of our sample was assigned to one of the treatment groups, while the control group contained the remaining 10 percent of the sample. ${ }^{7}$ Borrowers assigned to the treatment groups received quarterly email communications from Sallie Mae alerting them to the availability of their FICO Score and providing instructions on how

\footnotetext{
${ }^{6}$ http://www.fico.com/en/newsroom/fico-score-open-access-reaches-250-million-consumer-financialcredit-accounts

${ }^{7}$ Sallie Mae limited the control group to 10 percent of the sample in an effort to maximize the number of clients receiving information about Score availability while still preserving the ability to estimate the effect of the intervention.
} 
to access the information while control group members did not receive any communication about the program beyond what was stated on Sallie Mae's website.

All emails included a short description of the FICO Score and informed borrowers that their Score was available to view. The emails also included a link to log in to view the Score through Sallie Mae's website. Treatment group members received these communications once per quarter on the date that Scores were updated informing them that their FICO Score had been updated and, again, providing a link to log in to view the Score. Due to privacy considerations, no personalized information was included in the email itself. ${ }^{8}$

Borrowers in the treatment group were randomly assigned to receive one of three email messages: (1) baseline, (2) economic consequences, or (3) social influence. In the baseline condition, borrowers received only the information described above (Figure 2). The two additional conditions included the same information as the baseline email as well as additional messaging. In the economic consequences condition (Appendix Figure A.2a), clients received an email that was intended to emphasize the impact of the FICO Score on economic outcomes (e.g., "When you apply for credit - whether it's a credit card, car loan, student loan, apartment rental, or mortgage - lenders will assess your risk as a borrower..."). Building on research demonstrating the effectiveness of messaging informing individuals of prosocial actions of their peers (Allcott, 2011; Ayres, Raseman and Shih, 2013; Cialdini and Goldstein, 2004; Kast, Meier and Pomeranz, 2012), the social influence condition (Appendix Figure A.2b) included messaging informing readers that their peers were taking actions to improve their credit (e.g., "Many of your peers are building strong financial futures. You can, too, by effectively managing your student loans."). Our main analyses focus on variation between the control group and all treatment groups combined. However, Section V.D.i investigates the relative effectiveness of the different treatment messages.

\footnotetext{
${ }^{8}$ This requirement was not specific to Sallie Mae. Our understanding is that the FICO Score Open Access Program requires FICO Score information to be displayed on a password protected website rather than displayed in an email.
} 


\section{B. Experiment Timeline}

The three treatment groups in the main sample received eight quarterly emails starting in June of 2015. Each treatment group received their assigned message for three consecutive quarters (June, September, and December of 2015). However, beginning in 2016, all three treatment groups received only the content included in the baseline email message. In other words, clients in the economic consequences and social influence conditions began receiving the baseline message starting in March of 2016; clients in the baseline condition continued to receive the baseline message. The control group never received any direct communications about the program.

The experimental design included a separate population of 37,393 borrowers - the "discontinued sample" - that received quarterly emails for only three quarters. This sample was also split into three treatment message groups, and received quarterly email communications in June, September, and December of 2015. Our main analysis focuses on the 326,609 treatment group members who received quarterly communications through the end of the intervention in June of $2017 .{ }^{9}$ We use the discontinued sample to test whether continued communication has an impact on FICO Page views and on subsequent financial outcomes in Section V.C.

\section{Data}

\section{A. Email and FICO Score Page View Data}

Over the course of the study period, Sallie Mae tracked whether a borrower opened our treatment emails as well as each time a borrower viewed the FICO Score page on the web portal which users access online by logging in with their username and password. We use this information to construct weekly and quarterly indicators for whether the borrower viewed our treatment messages or their FICO Score page throughout the study period. Our data

\footnotetext{
${ }^{9}$ See Appendix Figure A.3 for a summary of the experimental timeline.
} 
on email open rates ranges from June 24, 2015 to June 9, 2016, while our FICO Score page view data ranges from June 26, 2015 (two days after the intervention began) to June 12, 2017.

\section{B. Credit Bureau Data}

Each quarter, Sallie Mae receives updated credit report information for each of their borrowers as part of routine business practice. The credit report information is provided by TransUnion, one of three major national credit reporting agencies, and is used to calculate the borrowers' FICO Score. The FICO Score is then made available to the borrower through the Open Access program. ${ }^{10}$ Since all borrowers in our sample hold a private student loan, FICO Scores existed for all borrowers in our sample.

In addition to the FICO Score itself, the quarterly credit file includes information on other financial outcomes including late payments and credit account activity at the individual borrower level. The late payments data includes indicators for whether the individual had any trade account that was more than 30,60, or 90 days past due in the last six months. An account is considered late if the borrower fails to make the minimum payment on-time. The credit account data includes the number of revolving trade accounts (e.g., credit cards), credit utilization (i.e., the percent of available credit used), and the total credit balance amount.

Table 1 presents summary statistics on demographics and baseline credit measures for our sample population as of June 2015 (i.e., prior to the launch of the experiment) by experimental condition. All individuals in our sample are student loan borrowers, with just over half still in school. Due to their young age (the average age in our population is 25), sample members are relatively new to credit with an average credit history of only 6.5 years. At the start of the experiment, the average FICO Score was 674, slightly lower than the

\footnotetext{
${ }^{10}$ Because the FICO Score Sallie Mae provides is based on this information from Trans Union, the Score made available to the borrower does not change within each quarter.
} 
national average of $700 .{ }^{11}$ Just under 70 percent of the sample had at least one revolving trade account with the average borrower holding 2.5 revolving trade accounts. Borrowers with at least one revolving trade account utilize just under 40 percent of their account limit. Roughly 14 percent of borrowers have had at least one account balance 30 or more days past due within the prior six months with half of those borrowers holding at least one account 90 days or more past due. Individual demographics and baseline credit history are balanced across the control and treatment conditions, consistent with the randomized design.

\section{Financial Literacy Survey Data}

In addition to collecting credit report data on the sample population, Sallie Mae conducted the "FICO and Financial Literacy Survey" to identify effects of the FICO Score Open Access Program on respondent financial literacy and FICO Score-specific knowledge. In June 2016, one year after the program began, Sallie Mae solicited survey responses from all current borrowers in the experimental sample. ${ }^{12}$ These data were linked to each borrower's treatment status to evaluate the effect of the intervention on survey responses.

\section{i. Survey Questionnaire}

The survey contained questions on the borrower's awareness and use of various financial communications and products provided by Sallie Mae with a specific focus on the FICO Score Open Access Program. Questions asked each borrower about the number of FICO Score views in the last year, familiarity with the concept of a FICO Score, and awareness of her personal FICO Score. ${ }^{13}$ Importantly, these self-reported Scores could then be linked to an individual's actual FICO Score to assess the accuracy of the self-report. Additionally, the survey contained a wide variety of questions to assess the borrower's general financial literacy

\footnotetext{
${ }^{11}$ www.fico.com/en/blogs/risk-compliance/us-average-fico-score-hits-700-a-milestone-for-consumers/

${ }^{12}$ Responses were solicited via email and borrowers had up to one month to participate. Sallie Mae sent email reminders encouraging borrowers to take the survey but did not provide an incentive for participating.

${ }^{13}$ Possible responses included FICO Score ranges of 0-299, 300-449, 450-549, 550-649, 650-749, 750-850 and more than 850 , or respondents could state that they did not know their FICO Score.
} 
including awareness of positive credit behaviors. Additional details of these questions are in

Appendix C. Lastly, participants responded to a series of demographic questions focusing on academic details such as college type, year and field of study, and student loan details.

\section{ii. Survey Response}

Of the more than 400,000 borrowers who were asked to participate, only 3,511 individuals completed the survey. While this low response rate is in line with previous survey requests sent by the lender, it raises some questions about the external validity of this data source. Appendix Table A.1, Panel A reveals several small but significant differences between survey respondents and non-respondents in baseline demographic and credit data drawn from the June 2015 TransUnion credit report. For example, survey respondents were slightly older (27 versus 25), more likely to be out of school (54 versus 45 percent), and had a higher FICO Score (696 versus 676) than non-respondents.

While the comparison of baseline characteristics reveals some differences between respondents and non-respondents, an examination of treatment status by survey response shows no such differences. Appendix Table A.1, Panel B shows that borrowers assigned to the treatment condition were equally likely to participate in the survey: 89.0 percent of survey respondents were assigned to the treatment condition versus 89.4 percent of non-respondents. So while our sample of survey respondents is unlikely to be representative of our full sample population, these results suggest that experimental comparisons within this select sample are still likely to be internally valid.

\section{Main Results}

\section{A. Dynamics of Email Open Rates and FICO Score Page Viewing Patterns}

We begin our analysis by investigating whether borrowers in the treatment group opened our quarterly emails and, if so, whether these communications led to an increase in the likelihood 
of viewing their FICO Score page. We utilize administrative data from Sallie Mae on daily email open rates and FICO Score page views.

Figure 3 presents email open rates for treatment group members by week for the first year of the intervention. Quarter labels correspond to the weeks in which the intervention emails were released. Figure 3a displays email open rates by week, while Figure 3b presents the percent of treatment group borrowers who had ever opened a treatment email by the week in question. Email open rates were highest in the week of the email release with very few borrowers opening the email after two weeks of the sent date. Twenty-one percent of treatment group members opened the first email and 48 percent of treatment group members opened at least one of the quarterly emails by the end of the first year of the intervention. This means that over half of borrowers in our treatment sample never received the information contained in our treatment messages.

Figure 4 mirrors Figure 3, but presents patterns of weekly FICO Score page views, rather than email open rates. Since all Sallie Mae clients had access to their FICO Score through the website regardless of treatment status, we present data for both treatment and control groups. ${ }^{14}$

Figure 4a shows that less than half a percent of control group members viewed their FICO Score page in most weeks with 12.3 percent of control group members viewing at least once by the end of year one and 19.0 percent by the end of the two-year intervention. This suggests that even in the absence of email communications about the program, some borrowers were aware of the availability of FICO Scores and did view them. However, the figures also show that receiving a quarterly email boosts FICO Score page views even further. Treatment group members saw a large spike in the number of FICO Score page views in the first week after each email was sent ranging between three and six percent of borrowers viewing their Scores in the week of the email release. Additionally, these effects do not fade over time: continued viewing is driven by a combination of borrowers who have already viewed their

\footnotetext{
${ }^{14}$ Note that our estimates of the fraction of borrowers viewing their Scores will be lower bound estimates since we did not capture Score views on the first two days of the campaign, see Section III.
} 
Scores doing so again as well as borrowers checking their Score for the first time late in the study period, as shown in Figure 4b. By the end of the first year of the intervention, 21.4 percent of treatment group members viewed their Score at least once, increasing to 31.4 percent by the end of the second year.

Table 2 presents the corresponding regression estimates of the effect of the treatment on FICO Score page views. Columns 1 and 3 show that treatment communications led to an increase of 8.1 and 12.4 percentage points in the likelihood of viewing one's FICO Score page by the end of years one and two, respectively. Columns 2 and 4 show that the intervention also led to significant increases in the number of page views. Appendix Table A.2 presents corresponding estimates at the quarter level.

While these estimates suggest that our intervention led to a significant increase in the likelihood of viewing one's Score through the Sallie Mae's website, this does not necessarily

tell us about the effects of the intervention on overall views. For example, treatment and control group members could be equally likely to have viewed their Scores during the study period, but the intervention simply caused treatment group borrowers to view their Scores through Sallie Mae's website rather than through a different source. We address this concern in Appendix B using survey data on views from all sources during the first year of the intervention and find treatment effects on the likelihood of ever having viewed one's FICO Score through any source that are nearly identical -8.0 versus 8.1 percentage points.

\section{B. First-Year Effects on Financial Outcomes}

In this section, we examine the effect of the intervention on individual financial outcomes captured by the TransUnion credit report. For each outcome, we first estimate a reduced form regression comparing outcomes by experimental group using first-differences to control for an individual's credit history prior to the experiment - the intent-to-treat (ITT) estimate. The regression model is as follows: 


$$
Y_{i}=\alpha_{0}+\alpha_{1} T_{i}+\varepsilon_{i}
$$

where the dependent variable is the difference in the financial outcome between the quarter prior to the experiment (June 2015) and the post-intervention quarter of interest and $T_{i}$ is an indicator for individual $i$ being randomly assigned to the treatment condition. Therefore, the coefficient of interest, $\alpha_{1}$, can be interpreted as the causal impact of sending quarterly emails about FICO Score availability on the within-person change in credit record outcomes, i.e., the difference-in-differences estimate comparing treatment and control groups before and after the start of the intervention. For our main specification, we consider the first-year impacts of the intervention; Section IV.C considers longer-term impacts.

A key component of our intervention is information about the availability of one's FICO Score. However, as detailed above, only 48 percent of individuals in the treatment group ever opened an email message from Sallie Mae in the first year of the intervention; and treatment group members were only 8 percentage points more likely to have ever viewed their FICO Score page than control group members. While the ITT estimates (presented in Panel A of our main results tables) are the policy relevant estimates for financial institutions considering a similar email campaign, we also present estimates from an analysis in which we use treatment status as an instrument for ever opening an email (Panel B) and for ever viewing one's FICO Score page (Panel C). The former provides an estimate of the treatmenton-the-treated effects of our informational messages, while the latter aims to isolate the effect of viewing one's FICO Score page, rather than simply reading the email.

The validity of these instrumental variables (IV) estimates depends on whether the additional informational content included in the intervention impacts financial behavior. We investigate the potential effect of several intervention components other than the FICO Score in Section V.C. and find no evidence that they directly affect financial outcomes. While this does not prove the validity of the exclusion restriction, it provides suggestive evidence that (at least for the components we study) the additional financial information contained in the 
treatment emails did not lead to a change in financial behaviors.

\section{i. Late Payments}

We begin our analysis by considering the effect of our intervention on the prevalence of late payments. Repayment behavior has important implications for borrowers' creditworthiness and overall financial health. Each payment period, borrowers have the option of paying off their balance or rolling over some or all of their debt to the following period. Not all borrowers may be able to pay their full balance at each billing period, nor may they want to if the interest rate on their credit card is lower than the cost of other credit alternatives (such as payday loans). However, failing to make a minimum payment - which is typically only between 1 and 4 percent of the total balance (Keys and Wang, 2019) - can lead to negative outcomes such as penalty fees, higher interest rates, and lower credit scores. ${ }^{15}$ Late fee penalties alone cost consumers more than $\$ 11$ billion per year. ${ }^{16}$ Therefore, many borrowers may benefit from successfully paying off their minimum balance each month.

Table 3 Column 1 presents the effect of the intervention on the change in likelihood of having at least one trade account balance past due for over 30 days within the past six months. Panel A shows that treatment group members were significantly less likely to have an account that was 30 days or more past due - a 0.7 percentage point decrease. Given that only 17.5 percent of control group members had a balance 30 or more days past due at the end of year 1, this is a relatively large (4 percent) reduction.

As mentioned above, Panels B and C present two alternative estimates which use treatment status as an instrument for the likelihood of opening an email and viewing one's FICO Score page, respectively. We find that opening the treatment email is associated with a 1.5 percentage point decrease in the likelihood of having an account 30 days or more past due. Turning to Panel C, we find that borrowers who were induced to view their FICO Score page

\footnotetext{
${ }^{15} \mathrm{https}$ :/ /www.americanexpress.com/us/content/financial-education/how-late-payments-affect-yourcredit-score.html; $\quad$ https://www.discover.com/credit-cards/resources/what-happens-if-you-dont-pay-acredit-card

${ }^{16}$ https://www.wsj.com/articles/amex-raises-its-fee-for-late-payments-1480069802
} 
as a result of the intervention are roughly half as likely as the control group to have a late payment (a reduction of 9.0 percentage points).

\section{ii. FICO Score}

We next turn to the effect of the treatment on the FICO Score itself, a summary metric that captures the net effect of the intervention on creditworthiness. Appendix Figure A.1 describes some of the key components impacting an individual's FICO Score, for example, payment history (i.e., whether balances are paid on time) accounts for 35 percent of the Score. The significant impact of our intervention on late payments suggests that we may expect to see an increase in the FICO Score itself; however, it is possible that the positive effect of reduced late payments is offset by other unobserved negative financial behaviors, leaving the net effect ambiguous.

Table 3 Column 2 presents the estimated effects of the treatment on the individual's FICO Score. Borrowers in the control group have an average FICO Score of 676 at the end of year 1. Our results show that receiving the quarterly emails significantly increased the average FICO Score of treatment group members by two-thirds of a point. Our instrumental variables estimates show that opening an email is associated with a 1.4 point increase, while borrowers who were induced to view their FICO Score page saw an 8.2 point increase.

To calibrate the size of the effect, the removal of a bankruptcy flag leads to FICO Score increases on the order of 10 to 15 points (Dobbie et al., 2016; Gross, Notowidigdo and Wang, Forthcoming). Separately, Appendix Figure A.1 shows that length of credit history accounts for 15 percent of the FICO Score; therefore, the relationship between credit history length and FICO Score provide us with another benchmark. In our sample, we find that an additional year of credit history is associated with a 1.1 point increase in FICO Scores, an effect that is only slightly larger than our ITT estimate of the effect of the intervention.

It is important to underscore that the FICO Score is designed as a measure of creditworthiness to be used in underwriting and is therefore not necessarily an accurate measure 
of financial health or well-being. However, financial institutions frequently use FICO Scores when making lending decisions or determining borrowing terms. For example, Gross, Notowidigdo and Wang (Forthcoming) find that a 10-point increase in credit scores is associated with a third of a percentage point decrease in the regular purchase APRs on new credit cards for consumers with credit scores between 600 and 700. Credit information is also used in other contexts. For example, credit reports are frequently used as inputs by landlords to determine eligibility for rental apartments or by employers in hiring decisions (Bartik and Nelson, 2016; Clifford and Shoag, 2016; Dobbie et al., 2016).

However, differential treatment as a function of credit scores is not always linear: banks frequently change lending terms at discrete cutoffs. For example, Federal Housing Authority loans (e.g., those issued through Fannie Mae) require a minimum credit score of 620 for most conforming fixed-rate mortgages, ${ }^{17}$ a common threshold used to define a subprime borrower.

Table 3 Column 3 looks at the effect of the intervention on having a FICO Score above 620. The treatment led to a significant increase of just under half a percentage point in the likelihood of having a Score over this threshold with a treatment-on-the-treated estimate of 0.9 percentage points. Borrowers who were induced to view their FICO Score page saw an increase in the likelihood of being above the threshold of 5.1 percentage points.

\section{iii. Other Credit Outcomes}

We next explore the impact of the intervention on other outcomes reported on borrowers' credit reports. Table 4 examines the effect of our intervention on general measures of credit usage including the likelihood of having an account, number of accounts, account balance, and credit utilization. Our analysis focuses on revolving trade activity (most commonly, credit card accounts). These are trade accounts that are plausibly easy to open or close in response to learning about one's FICO Score unlike, for example, a mortgage or an auto loan. The first column presents estimates of the effect of the treatment on the likelihood

\footnotetext{
${ }^{17}$ https://www.fanniemae.com/content/guide/selling/b3/5.1/01.html\#Minimum.20Credit.20Score.20Requirements
} 
of having any open revolving credit account. We find that the intervention caused a small but significant increase of 0.3 percentage points in the likelihood of having at least one account (on a base of 76 percent among control group members) - an important step towards establishing a credit history. We observe a similarly small but significant increase in the number of accounts held (an increase of 0.01 accounts) and an insignificant increase in the total balance. We also find that the effect of the treatment on credit utilization is small and not statistically significant.

We perform a multiple hypothesis correction following List, Shaikh and Xu (2016) that includes all outcomes examined in Tables 3 and 4 . While all of the outcomes considered in our main analysis Table 3 remain significant after this correction, the estimated effect of treatment on likelihood of having an account and number of accounts are no longer significant.

\section{Heterogeneity of Treatment Effects}

\section{i. Baseline FICO Score}

One question is whether the intervention was effective for the people who needed help the most - those with lower FICO Scores - or whether the treatment only moved behavior among those who were already performing well on this metric. In Figure 5, we examine heterogeneity of the treatment effect on having a late payment and on FICO Score by preintervention FICO Score decile.

Figure 5a shows that, while the point estimates for the effect of the treatment on late payments are negative for all deciles, the treatment effect is largely consolidated among borrowers in the second decile (borrowers with baseline FICO Scores between 600 and 638). Specifically, while the treatment led to an average decrease in late payments of 0.4 percentage points across the other nine deciles, the treatment led to a decrease of 3.2 percentage points for borrowers in the second decile. Consistent with payment history serving as a key input for FICO Scores, Figure 5b also finds the largest effects on FICO Scores for borrowers in 
the second decile, although the differences across deciles are not as pronounced as for late payments.

These patterns may be partly due to the fact that late payments are concentrated in the bottom two deciles. Fifty-five percent of borrowers in the bottom two deciles have late payments at baseline compared to only 3 percent in the other eight deciles combined. It is somewhat surprising that we do not see similarly large effects among borrowers in the

first decile. However, one key difference between borrowers in these bottom two deciles is the propensity to have a late payment 90 days or more past due (i.e., to have a delinquent account). Two-thirds of the past-due accounts in the first decile are 90 days or more past due compared to only one-third in the second decile. This suggests that our intervention might be particularly helpful for borrowers who have engaged in negative financial behaviors but do not have the most deeply entrenched financial problems.

\section{ii. Other Borrower Characteristics}

It is also possible that the treatment had differential effects on borrowers of different age groups. Younger borrowers are less likely to have financial experience and may be less aware of how to improve their own creditworthiness; therefore, we might expect that our intervention would be particularly successful in this population. Alternatively, older borrowers may respond more to the intervention since they have more actions available to take as a result of having more established finances. A related yet distinct categorization of borrowers is whether they are in school versus out of school. For example, borrowers who are out of school are likely to be working and may have more financial responsibilities. While these two sets of borrower characteristics are correlated, 30 percent of borrowers who are still in school are above the median age.

Appendix Table A.3 Columns 1 and 2 present treatment effects by age for late payments and FICO Score, respectively, comparing borrowers who are above or below the median age of 23 years old at the start of the intervention. Columns 3 and 4 present treatment effects for 
the same outcomes by student status, comparing borrowers who are still in school with those who are out of school. We find no significant differences in treatment effects by age or student status for either financial outcome, though the point estimates suggest that the effects are slightly larger among borrowers hypothesized to have more financial responsibilities, i.e., older borrowers and those who are out of school.

\section{Long-Term Effects}

The estimated treatment effects presented thus far are evaluated one year from the start of the intervention, from June 2015 to June 2016. To examine both the longer-term treatment effects and how the effects evolve over time, Figure 6 presents ITT estimates quarterly for the full two-year study period from June 2015 to June 2017.

Figure 6a presents quarterly treatment effects for the likelihood having a late payment of 30 or more days past due. Our results show that the size of the treatment effect is greatest approximately 12 to 15 months from the start of the intervention. After 15 months, the treatment effect attenuates and by the end of the two-year period is no longer statistically significant. Figure $6 \mathrm{~b}$ presents the estimated effect of the treatment on borrowers' FICO Scores in each quarter. Here again we see the estimated coefficient is largest one year from the start of the intervention, however, the effect remains fairly consistent through the end of the two-year study period.

\section{Mechanisms}

The previous section shows that our informational campaign led to a reduction in late payments and an increase in FICO Scores. In the current section, we investigate potential mechanisms driving these effects. 


\section{A. Personal FICO Score Knowledge}

Previous research has shown that people are often overly confident about their own knowledge and ability in a range of domains (Kahneman and Tversky, 1996; Fischhoff, Slovic and Lichtenstein, 1977), including evidence of overestimation in the context of credit scores (Perry, 2008). One potential mechanism by which the intervention could operate is by correcting biases in perceptions of one's own FICO Score. We examine this possibility using information from our second data source, the FICO and Financial Literacy Survey, which asked respondents several questions about their knowledge of personal financial information, specifically, their own FICO Score. Respondents were asked if they knew their FICO Score and, if so, were asked to indicate their Score within a 100 to 150 point range. Using data from our administrative credit reports, we can then verify the accuracy of these self-reported Scores. Consequently, our definition of accuracy corresponds to knowing the correct 100 to 150 point range.

Column 1 of Table 5 shows that while over three-quarters of control group members reported knowing their FICO Score range, treatment group members were 4.3 percentage points more likely to report knowing their Score. A larger difference emerges when comparing the accuracy of these responses to the corresponding data from respondents' TransUnion credit reports. Column 2 shows that treatment group members are 7.1 percentage points more likely to report an accurate FICO Score range on a base of 51.5 percent accuracy among control group members - a 14 percent increase. Columns 3 and 4 decompose this gap between reported and accurate knowledge to examine the effects of the intervention on the likelihood of overestimating versus underestimating one's FICO Score, respectively. We find that receiving a treatment message significantly decreased the likelihood of borrowers reporting an overestimate of their FICO Score by 3.4 percentage points, but had no significant impact on the likelihood of underestimating one's Score. ${ }^{18}$

\footnotetext{
${ }^{18}$ We test whether the degree of debiasing as reflected in the survey corresponds to the degree of behavioral change in the field by modeling the association between FICO Score knowledge and late payments in the control group. We find control group members who accurately reported their FICO Score in the survey were
} 
These findings suggest that the intervention provided borrowers with important feedback that they could use to calibrate their personal creditworthiness. Our findings are consistent with existing evidence of overoptimism in knowledge of personal creditworthiness (Perry, 2008) and with evidence that over-confidence and over-optimism negatively affect performance in other areas (Biais et al., 2005; Camerer and Lovallo, 1999). Our evidence suggests that debiasing these misperceptions may lead to improvements in financial behaviors.

\section{B. Reason Codes}

As mentioned in Section II, all financial institutions that made FICO Scores available through the Open Access initiative were required to include two reason codes that provided an explanation of the primary factors contributing to their Score along with the FICO Score itself. Although our estimate of the effect of the FICO Score page as a whole is the relevant estimate for evaluating the impact of the FICO Score Open Access initiative, in this section we explore the relative effectiveness of these two components: the FICO Score and the reason codes.

In our sample of borrowers, the top three categories of reason codes shown to borrowers pertain to credit history length (e.g., "Length of time accounts have been established"), debt levels (e.g., "Proportion of loan balances to loan amounts is too high"), and late payments (e.g., "Number of accounts with delinquency"). Some reason codes refer to specific actions a borrower can take to improve her Score. For example, at baseline 34 percent of our sample was shown a reason code directly related to late payments, one of our focal outcomes. On the other hand, 30 percent of borrowers receive information with no direct implications for action (e.g., "Length of time accounts have been established").

Table 6 estimates treatment effects on late payments separately for those who received (versus did not receive) a delinquency reason code (Column 1) as well as for those who

less likely to have a late payment. Conversely, those who overestimated their Score were more likely to have a late payment than those who did not. A back of the envelope calculation suggests that the FICO Score knowlege pathway accounts for between one-quarter and one-half of the treatment effect on late payments. 
received any actionable (versus not actionable) reason code (Column 2) at the start of the intervention. The sign on the interaction term coefficient in Column 1 suggests that the treatment effects on late payments are larger for individuals with baseline delinquency reason codes. Yet, the intervention also led to a statistically significant decrease in the likelihood of having a late payment at the end of the first year among treatment group members with no delinquency reason code at baseline. Column 2 also shows significant treatment effects for borrowers who did not receive any actionable reason code at baseline.

While we cannot rule out that reason codes had an independent effect on financial behavior, these findings suggest that the reason codes are not the only component of the viewing page driving behavior change. Additionally, this suggests that the decrease in late payments is unlikely to be solely driven by individuals reconciling previous past due accounts, but that the intervention reduced the likelihood that an individual would enter into delinquency going forward. ${ }^{19}$

\section{Repeated Reminders}

Consistent with an account of limited attention (Bordalo, Gennaioli and Shleifer, 2013; Chetty, Looney and Kroft, 2009; Malmendier and Lee, 2011), another possibility is that our intervention did not provide borrowers with any new information, but acted as a repeated reminder (Cadena and Schoar, 2011; Karlan et al., 2016). In this section, we examine a separate sample - our "discontinued sample" - who were randomly assigned to received quarterly email communications for only three quarters rather than throughout the two-year intervention as in our main treatment sample. This sample allows us to test the impact of additional email communications on viewing rates and financial outcomes to determine if repeated reminders led to improved outcomes.

Figure 7 presents weekly FICO Score page view rates for the control group, discontin-

\footnotetext{
${ }^{19} \mathrm{~A}$ parallel analysis that considers the effect of the treatment by whether a borrower had a late payment at baseline (rather than baseline delinquency reason code) shows similar patterns-we observe significant treatment effects on late payments even among those without a late payment on their credit report at the start of the intervention.
} 
ued sample, and the main treatment sample. The figure shows that the FICO Score page view rates for the main treatment sample and the discontinued sample are virtually indistinguishable for the first three quarters of the email campaign, which is expected since the two groups received the same treatment during this time period. However, starting in March 2016 — when the discontinued sample stopped receiving email communications - the discontinued group's view rates began to closely track the control group rather than the treatment group.

Table 7 shows the regression estimates for the effect of the main versus discontinued treatment on viewing and financial behaviors. Column 1 presents treatment effects for the two treatment samples on the likelihood of viewing one's Score before March 2016, the last quarter in which the two groups had received the same treatment. Unsurprisingly, we see no difference in treatment effects between the two groups prior to March 2016. However, starting in the following quarter we see the two groups diverge. Column 2 shows that one year after the discontinued group stopped receiving the quarterly emails, the treatment effects on viewing rates for the main sample were twice as large as those for the discontinued group 10.9 versus 5.3 percentage points.

While our results show that individuals who continue to receive reminders to view their FICO Score page are more likely to do so than individuals who received reminders for a limited time, it is not necessarily true that repeated reminders will lead to larger changes in behavior. For example, borrowers may take a discrete action upon first viewing their Score - e.g., signing up for automatic payment on a credit card - that could then have a persistent positive effect on financial outcomes.

Table 7 Columns 3 and 4 present treatment effects on the likelihood of having a late payment and borrower FICO Score, respectively, for the two samples one year after the discontinued group stopped receiving communications. As we saw in Section IV.C, the effects for the main treatment group are attenuated, but largely persistent almost two years after the program's inception. Similarly, the estimates for the discontinued sample are only 
slightly smaller than those in the main treatment group: there is no statistically significant difference between the financial outcomes of those who continued to receive emails and those who stopped receiving emails a year prior.

These results are consistent with a story in which the long term effects on financial outcomes come from a one-time change in behavior rather than a sustained behavioral change. An alternative story that is also consistent with these results is that individuals who view their Score only after receiving repeated reminders are less likely to respond to the treatment. We explore the relationship between the timing of viewing patterns and changes in financial outcomes in Appendix Table A.4. Columns 1 and 2 exclude borrowers who viewed their FICO Score page for the first time in year 2 while columns 3 and 4 exclude those who viewed their Score for the first time in year 1. We consider the effect of our treatment in these two samples on the likelihood of ever having a late payment in year 1 (Columns 1 and $3)$ and separately in year 2 (Columns 2 and 4). We find that treatment effects in year 1 are only significant for the sample that includes borrowers who viewed their FICO Score page in year 1; the results for this sample are somewhat smaller in year 2 (consistent with Figure 6). However, we see small and not statistically significant results in both years for the sample that excludes borrowers who viewed their Score in the first year of the intervention. This suggests that borrowers who wait to view until later in the intervention are less likely to change their behavior in response to the information provided.

\section{Additional Informational Content in Email}

In addition to the ability to view one's FICO Score page, the treatment email message includes content describing the importance of the FICO Score as well as hyperlinks to additional information about FICO Scores and general financial literacy. If this additional infor-

mation contributes to changes in financial behavior, our IV estimates will be overstated. ${ }^{20}$

\footnotetext{
${ }^{20}$ Similarly, the exclusion restriction for our estimates which instrument for ever opening an email from Sallie Mae will be violated if receipt of the message impacts financial behavior even if the email is never opened.
} 
In this section we investigate the potential effect of this additional informational content on financial behavior.

\section{i. Treatment Effects by Message Type}

The results in Section IV focus on the effect of receiving any treatment message. However, two experimental groups received additional information in their email messages for the first three quarters of the intervention. Borrowers in the social influence and economic consequences treatment groups received information about peer credit behavior and financial consequences of low FICO Scores, respectively. If borrowers were unaware of how FICO Scores impact the cost of credit, the economic consequences message may prompt additional changes in behavior. At the same time, borrowers may be additionally motivated to improve their FICO Score if they are told people like them are doing so (Allcott, 2011; Ayres, Raseman and Shih, 2013; Cialdini and Goldstein, 2004; Kast, Meier and Pomeranz, 2012).

Figure 8 mirrors the analysis in Figure 4, but displays FICO Score page view rates separately for the three treatment messages for the first year of the intervention. The figure shows that the viewing rates - both within a given week and the likelihood of ever viewing by a given week - are very similar across treatment messages. If anything, the baseline message very slightly outperformed the two messages that contained additional information, though this difference is quite small and not statistically significant.

Table 8 presents treatment effects for late payments and FICO Score separately by treatment message type: baseline, economic consequences, and social influence. The F-test for equality of treatment effects across the three messages suggests that the estimates are not significantly different across treatment groups. This is somewhat unsurprising given the relatively similar FICO Score page view rates across the three treatment groups. While research has shown nudges of this type can be effective in some contexts, we find no evidence that the additional message content impacted behavior. 


\section{ii. General Financial Information}

One other possibility is that the intervention may have translated to differences in financial knowledge by providing links to general financial education resources. For example, these resources could make people more familiar with the concept of a credit score or good types of credit behavior. To the extent that borrowers were previously unaware that a metric like a credit score existed, that awareness could have, in and of itself, led them to take actions to improve it.

Appendix Table A.5 uses data from the FICO and Financial Literacy Survey which contains questions on knowledge of several financial concepts including knowledge of good credit behaviors, familiarity with FICO Scores, and a financial literacy quiz to address the effect of the intervention on general financial knowledge. We find no effects of the treatment on borrowers' ability to correctly identify any individual credit behavior as positive or negative. It is interesting to note that the control means for accurately identifying each behavior are quite high - over 90 percent for all but one measure - suggesting that many respondents were already aware of the activities necessary to improve their credit. We also find no effects of the treatment on borrower's general FICO Score knowledge (i.e., confidence they could explain what a credit score is to a friend) or performance on the financial literacy quiz.

\section{Conclusion}

Findings from our field experiment indicate that viewing one's FICO Score influences financial behaviors. Borrowers who were randomly assigned to receive communications informing them that their Score was available to view were less likely to have late payments and had higher FICO Scores overall. These effects largely persisted throughout the full two-year intervention. Survey results provide evidence that borrowers in the treatment group were less likely to overestimate their Score relative to those in the control group. It is particularly encouraging that this intervention appears to spur positive behavior change among a relatively 
young population that is new to credit and may therefore yield long term benefits from immediate behavior change-for example, delinquent behavior remains on an individual's credit history for up to seven years.

The FICO Score provides a single number that allows for easy tracking of a disparate set of actions related to creditworthiness. This personalized, quantified, dynamic measure allows individuals to monitor and track their progress over time. This holistic financial metric may be particularly well suited for goal-setting. For example, a large body of literature documents goal-setting behavior in which people try to achieve a certain level of performance as a function of a numeric cue, such as a race finishing time or personal best score in a game (Anderson and Green, 2018; Locke and Latham, 2002; Pope and Simonsohn, 2011; Allen et al., 2016). However, these types of goals can best be set and managed when they are able to be quantified through a single number. ${ }^{21}$ Similar metrics that summarize a broad set of outcomes may be effective in other areas as well, such as promoting overall health scores to encourage better health habits or promoting overall efficiency scores to encourage better time management.

Our findings demonstrate the potential for targeted, low-cost, scalable interventions to positively impact financial decision making and improve consumer financial welfare. More generally, our findings point to possible benefits of personalizing financial interventions, consistent with individual self-reports that personal experience is a key driver of financial learning (Hilgert, Hogarth and Beverly, 2003) and with recent efforts to promote "just in time" interventions that are timed to personal financial events (Fernandes, Lynch Jr and Netemeyer, 2014).

One limitation of our experiment is that we are unable to see borrowers' full financial pictures. Since we only observe information reported to credit bureaus, we cannot rule out the possibility that the intervention is encouraging people to prioritize financial behaviors that are directly tied to their credit score to the detriment of other aspects of their financial

\footnotetext{
${ }^{21}$ For example, see Erez (1977); Seligman and Darley (1977); Walford et al. (1978) for studies in the health and medical literature documenting positive behavioral responses to monitoring.
} 
lives we do not observe, such as income and savings (Beshears et al., 2019; Medina, 2017; Sussman and O'Brien, 2016). While our intervention shows positive effects on behaviors recorded in credit bureau data, future work should examine the impact of viewing one's score on other aspects of financial health.

\section{References}

Agarwal, Sumit, John C Driscoll, Xavier Gabaix, and David Laibson. 2008. "Learning in the Credit Card Market." National Bureau of Economic Research Working Paper 13822.

Agarwal, Sumit, Souphala Chomsisengphet, Neale Mahoney, and Johannes Stroebel. 2014. "Regulating consumer financial products: Evidence from credit cards." The Quarterly Journal of Economics, 130(1): 111-164.

Allcott, Hunt. 2011. "Social norms and energy conservation." Journal of Public Economics, 95(9): 1082-1095.

Allen, Eric J, Patricia M Dechow, Devin G Pope, and George Wu. 2016. "Reference-dependent preferences: Evidence from marathon runners." Management Science, 63(6): 1657-1672.

Anderson, Ashton, and Etan A Green. 2018. "Personal bests as reference points." Proceedings of the National Academy of Sciences, 115(8): 1772-1776.

Ayres, Ian, Sophie Raseman, and Alice Shih. 2013. "Evidence from two large field experiments that peer comparison feedback can reduce residential energy usage." The Journal of Law, Economics, and Organization, 29(5): 992-1022.

Bartik, Alexander Wickman, and Scott Nelson. 2016. "Credit Reports as Resumes: The incidence of pre-employment credit screening." Unpublished Manuscript. 
Benartzi, Shlomo, and Richard H Thaler. 2001. "Naive diversification strategies in defined contribution saving plans." American Economic Review, 91(1): 79-98.

Bertrand, Marianne, and Adair Morse. 2011. "Information disclosure, cognitive biases, and payday borrowing." The Journal of Finance, 66(6): 1865-1893.

Beshears, John, James J Choi, David Laibson, Brigitte C Madrian, and William L Skimmyhorn. 2019. "Borrowing to Save? The Impact of Automatic Enrollment on Debt." National Bureau of Economic Research Working Paper 25876.

Bhargava, Saurabh, and Dayanand Manoli. 2015. "Psychological frictions and the incomplete take-up of social benefits: Evidence from an IRS field experiment." American Economic Review, 105(11): 3489-3529.

Biais, Bruno, Denis Hilton, Karine Mazurier, and Sébastien Pouget. 2005. "Judgemental overconfidence, self-monitoring, and trading performance in an experimental financial market." The Review of Economic Studies, 72(2): 287-312.

Bordalo, Pedro, Nicola Gennaioli, and Andrei Shleifer. 2013. "Salience and consumer choice." Journal of Political Economy, 121(5): 803-843.

Bracha, Anat, and Stephan Meier. 2019. "Misjudge the Nudge? The (Mixed) Effect of Reminders on Creditworthiness." Federal Reserve Bank of Boston Working Paper.

Cadena, Ximena, and Antoinette Schoar. 2011. "Remembering to Pay? Reminders vs. Financial Incentives for Loan Payments." National Bureau of Economic Research Working Paper 17020.

Camerer, Colin, and Dan Lovallo. 1999. "Overconfidence and excess entry: An experimental approach." The American Economic Review, 89(1): 306-318.

Carpenter, Jeffrey P, Emiliano Huet-Vaughn, Peter Hans Matthews, Andrea Robbett, Dustin Beckett, and Julian C Jamison. 2017. "Choice Architecture to 
Improve Financial Decision Making." Consumer Financial Protection Bureau Office of Research Working Paper.

CFPB. 2015. "The Consumer Credit Card Market." Consumer Financial Protection Bureau.

Chetty, Raj, Adam Looney, and Kory Kroft. 2009. "Salience and taxation: Theory and evidence." The American Economic Review, 99(4): 1145-1177.

Choi, James J, David Laibson, Brigitte C Madrian, and Andrew Metrick. 2009. "Reinforcement learning and savings behavior." The Journal of Finance, 64(6): 2515-2534.

Cialdini, Robert B, and Noah J Goldstein. 2004. "Social influence: Compliance and conformity." Annual Review of Psychology, 55: 591-621.

Clifford, Robert, and Daniel Shoag. 2016. "No More Credit Score: Employer Credit Check Bans and Signal Substitution.” Federal Reserve Bank of Boston Working Paper 16-10.

Dobbie, Will, Paul Goldsmith-Pinkham, Neale Mahoney, and Jae Song. 2016. "Bad Credit, No Problem? Credit and Labor Market Consequences of Bad Credit Reports." National Bureau of Economic Research Working Paper 22711.

Erez, Miriam. 1977. "Feedback: A necessary condition for the goal setting-performance relationship." Journal of Applied Psychology, 62(5): 624.

Fernandes, Daniel, John G Lynch Jr, and Richard G Netemeyer. 2014. "Financial literacy, financial education, and downstream financial behaviors." Management Science, 60(8): 1861-1883.

Fischhoff, Baruch, Paul Slovic, and Sarah Lichtenstein. 1977. "Knowing with certainty: The appropriateness of extreme confidence." Journal of Experimental Psychology: Human perception and performance, 3(4): 552 . 
Gross, David B, and Nicholas S Souleles. 2002. "An Empirical Analysis of Personal Bankruptcy and Delinquency." Review of Financial Studies, 15(1): 319-347.

Gross, Tal, Matthew J Notowidigdo, and Jialan Wang. Forthcoming. "The Marginal Propensity to Consume over the Business Cycle." American Economic Journal: Macroeconomics.

Hilgert, Marianne A, Jeanne M Hogarth, and Sondra G Beverly. 2003. "Household Financial Management: The Connection Between Knowledge and Behavior." Federal Resserve Bulletin, 89: 309.

Kahneman, Daniel, and Amos Tversky. 1996. "On the reality of cognitive illusions." Psychological Review.

Karlan, Dean, Margaret McConnell, Sendhil Mullainathan, and Jonathan Zinman. 2016. "Getting to the top of mind: How reminders increase saving." Management Science, 62(12): 3393-3411.

Kast, Felipe, Stephan Meier, and Dina Pomeranz. 2012. "Under-Savers Anonymous: Evidence on Self-Help Groups and Peer Pressure as a Savings Commitment Device." National Bureau of Economic Research Working Paper 18417.

Keys, Benjamin J, and Jialan Wang. 2019. "Minimum payments and debt paydown in consumer credit cards." Journal of Financial Economics, 131(3): 528-548.

Kling, Jeffrey R, Sendhil Mullainathan, Eldar Shafir, Lee C Vermeulen, and Marian V Wrobel. 2012. "Comparison friction: Experimental evidence from Medicare drug plans." The Quarterly Journal of Economics, 127(1): 199-235.

Lacko, James M, and Janis K Pappalardo. 2010. "The failure and promise of mandated consumer mortgage disclosures: Evidence from qualitative interviews and a controlled experiment with mortgage borrowers." The American Economic Review, 100(2): 516-521. 
List, John A, Azeem M Shaikh, and Yang Xu. 2016. "Multiple Hypothesis Testing in Experimental Economics." National Bureau of Economic Research Working Paper 21875.

Locke, Edwin A, and Gary P Latham. 2002. "Building a practically useful theory of goal setting and task motivation: A 35-year odyssey." American psychologist, 57(9): 705.

Malmendier, Ulrike, and Young Han Lee. 2011. "The bidder's curse." The American Economic Review, 101(2): 749-787.

Medina, Paolina C. 2017. "Selective Attention in Consumer Finance: Evidence from a Randomized Intervention in the Credit Card Market." Unpublished Manuscript.

Perry, Vanessa Gail. 2008. "Is ignorance bliss? Consumer accuracy in judgments about credit ratings." Journal of Consumer Affairs, 42(2): 189-205.

Ponce, Alejandro, Enrique Seira, and Guillermo Zamarripa. 2017. "Borrowing on the Wrong Credit Card? Evidence from Mexico." The American Economic Review, 107(4): 1335-1361.

Pope, Devin, and Uri Simonsohn. 2011. "Round numbers as goals: Evidence from baseball, SAT takers, and the lab." Psychological Science, 22(1): 71-79.

Seira, Enrique, Alan Elizondo, and Eduardo Laguna-Muggenburg. 2017. "Are Information Disclosures Effective? Evidence from the Credit Card Market." American Economic Journal: Economic Policy, 9(1): 277-307.

Seligman, Clive, and John M Darley. 1977. "Feedback as a means of decreasing residential energy consumption." Journal of Applied Psychology, 62(4): 363.

Sussman, Abigail B, and Rourke L O'Brien. 2016. "Knowing When to Spend: Unintended Financial Consequences of Earmarking to Encourage Savings." Journal of Marketing Research. 
Svenson, Ola. 1981. "Are we all less risky and more skillful than our fellow drivers?" Acta psychologica, 47(2): 143-148.

Walford, S, EAM Gale, SP Allison, and RB Tattersall. 1978. "Self-monitoring of blood-glucose: improvement of diabetic control." The Lancet, 311(8067): 732-735. 
Table 1: Summary Statistics

\begin{tabular}{|c|c|c|c|c|c|}
\hline & $\begin{array}{r}\text { Control } \\
(1)\end{array}$ & $\begin{array}{r}\text { Treatment } \\
(2)\end{array}$ & $\begin{array}{r}\text { Discontinued Sample } \\
(3)\end{array}$ & $\begin{array}{r}\text { F-stat } \\
(4)\end{array}$ & $\begin{array}{r}\text { prob }>F \\
(5)\end{array}$ \\
\hline \multicolumn{6}{|l|}{ Panel A: Demographics } \\
\hline Age & 25.0 & 25.0 & 25.0 & 1.01 & 0.31 \\
\hline Currently in School (\%) & 57.1 & 56.7 & 56.9 & 2.58 & 0.11 \\
\hline \multicolumn{6}{|l|}{ Panel B: Credit History } \\
\hline Months in Credit File & 77.0 & 77.5 & 77.1 & 1.41 & 0.24 \\
\hline \multicolumn{6}{|l|}{ Balance Past Due (\%) } \\
\hline $30+$ Days & 13.5 & 13.7 & 13.4 & 1.54 & 0.21 \\
\hline $60+$ Days & 9.2 & 9.2 & 9.2 & 0.00 & 0.94 \\
\hline $90+$ Days & 6.7 & 6.7 & 6.6 & 0.11 & 0.74 \\
\hline \multicolumn{6}{|l|}{ Revolving Trade Activity } \\
\hline Any Account (\%) & 69.5 & 69.3 & 69.1 & 0.34 & 0.56 \\
\hline Number of Accounts & 2.5 & 2.5 & 2.5 & 0.07 & 0.79 \\
\hline Credit Utilization (\%) & 39.6 & 39.7 & 39.9 & 0.16 & 0.69 \\
\hline FICO Score & 674 & 674 & 674 & 0.27 & 0.61 \\
\hline $\mathrm{N}$ & 42,964 & 326,609 & 37,393 & & \\
\hline
\end{tabular}

Source: Sallie Mae and TransUnion, June 2015.

Means shown for the control group (column 1), main treatment sample combined (column 2) and the discontinued sample (column 3) shown separately.

F-test for equality for main treatment versus control group means.

Balance past due measures assessed over the prior six months.

Credit utilization evaluated only for borrowers with at least one revolving account.

Table 2: First Stage: FICO Score Page Views

\begin{tabular}{lrrrr}
\hline & \multicolumn{2}{c}{ By Year 1 End } & \multicolumn{2}{c}{ By Year 2 End } \\
\cline { 3 - 5 } & Ever View & Number of Views & Ever View & Number of Views \\
& $(1)$ & $(2)$ & $(3)$ & $(4)$ \\
\hline Treatment & $0.0813^{* * *}$ & $0.1931^{* * *}$ & $0.1238^{* * *}$ & $0.4367^{* * *}$ \\
& $(0.0017)$ & $(0.0051)$ & $(0.0021)$ & $(0.0098)$ \\
\hline Control Mean & 0.124 & 0.227 & 0.192 & 0.449 \\
$\mathrm{~N}$ & 369,601 & 369,601 & 369,601 & 369,601 \\
\hline \hline
\end{tabular}

Source: Sallie Mae, June 2015 to June 2017.

Outcomes: ever viewed (columns $1 \& 3$ ) and number of views (columns $2 \& 4$ )

by the end of year 1 and 2 of the intervention, respectively.

Robust standard errors in parentheses.

${ }^{*} p<0.10,{ }^{* *} p<0.05,{ }^{* * *} p<0.01$ 
Table 3: Treatment Effects: Main Outcomes

$30+$ Day Late Payment $\quad$ FICO Score $\quad$ FICO $>620$

(1)

(2)

\section{Panel A: Intent to Treat}

Treatment

$(0.0021)$

Panel B: IV for Email Open Rate

$$
-0.0073^{* * *}
$$

$-0.0151^{* * *}$

(0.0044)

$0.6700^{* * *}$
$(0.2265)$

$(0.2265)$

$1.3926^{* * *}$

$(0.4708)$

Panel C: IV for FICO Page View Rate

$$
-0.0896^{* * *}
$$

Control Mean

0.175

369,601

$\mathrm{N}$ $8.2425^{\text {*** }}$ (2.7872)

676

$0.0042^{* *}$

(0.0018) 369,601 
Table 4: Treatment Effects: Additional Outcomes on Revolving Credit Account Activity

$$
\text { Any Account \# Accounts \% Credit Used Balance Amount }
$$

\begin{tabular}{|c|c|c|c|c|}
\hline \multicolumn{5}{|c|}{ Panel A: Intent to Treat } \\
\hline \multirow[t]{2}{*}{ Treatment } & $0.0029^{*}$ & $0.0131^{* *}$ & 0.0469 & 22.7892 \\
\hline & $(0.0017)$ & $(0.0067)$ & $(0.1803)$ & $(25.8924)$ \\
\hline \multicolumn{5}{|c|}{ Panel B: IV for Email Open Rate } \\
\hline \multirow[t]{2}{*}{ Ever Opened Email } & $0.0060^{*}$ & $0.0273^{* *}$ & 0.0909 & 47.3691 \\
\hline & $(0.0034)$ & $(0.0138)$ & $(0.3490)$ & $(53.8185)$ \\
\hline \multicolumn{5}{|c|}{ Panel C: IV for FICO Page View Rate } \\
\hline \multirow[t]{2}{*}{ Ever Viewed Score } & $0.0356^{*}$ & $0.1615^{* *}$ & 0.4909 & 280.3666 \\
\hline & $(0.0204)$ & $(0.0819)$ & $(1.8853)$ & $(318.5089)$ \\
\hline Control Mean & 0.758 & 2.778 & 39.542 & 3717.136 \\
\hline $\mathrm{N}$ & 369,601 & 369,601 & 232,503 & 369,601 \\
\hline
\end{tabular}

Source: Sallie Mae and TransUnion, June 2015 to June 2016.

Outcomes: indicator for any open revolving trade account (column 1), number of accounts (column 2), percent of credit used among borrowers with at least one account (column 3), and balance amount (column 4).

All outcomes are first-differences between June 2015 and June 2016.

Panel A: ITT estimate comparing treatment and control groups.

Panel B: instruments ever opening treatment email with treatment status.

Panel C: instruments ever viewing FICO Score page with treatment status.

Robust standard errors in parentheses.

${ }^{*} p<0.10,{ }^{* *} p<0.05,{ }^{* * *} p<0.01$

Table 5: Personal FICO Score Knowledge

\begin{tabular}{lrrrr}
\hline & Reported & Accurate & & \\
& Knowledge & Knowledge & Overestimate & Underestimate \\
& $(1)$ & $(2)$ & $(3)$ & $(4)$ \\
\hline Treatment & $0.0433^{*}$ & $0.0712^{* * *}$ & $-0.0343^{* *}$ & 0.0065 \\
& $(0.0224)$ & $(0.0269)$ & $(0.0165)$ & $(0.0192)$ \\
\hline Control Mean & 0.773 & 0.515 & 0.108 & 0.149 \\
$\mathrm{~N}$ & 3,511 & 3,511 & 3,511 & 3,511 \\
\hline \hline
\end{tabular}

Source: FICO and Financial Literacy Survey, June 2016.

Outcomes: indicators for reporting awareness of personal FICO Score (column 1), recalling accurate personal 100-150 point FICO Score range (column 2), and reporting overestimated or underestimated FICO Score (columns $3 \& 4$ ).

Treatment group includes borrowers who received a message at any point in the intervention.

Each column indicates the proportion of the total population surveyed responding as stated.

Robust standard errors in parentheses.

${ }^{*} p<0.10,{ }^{* *} p<0.05,{ }^{* * *} p<0.01$ 
Table 6: Treatment Effects by Baseline Reason Code

\begin{tabular}{|c|c|c|}
\hline \multicolumn{3}{|c|}{ Late Payment } \\
\hline Treatment $(\mathrm{T})$ & $\begin{array}{l}-0.0055^{\text {*** }} \\
(0.0019)\end{array}$ & $\begin{array}{l}-0.0041^{*} \\
(0.0024)\end{array}$ \\
\hline T x Delinquency Code & $\begin{array}{r}-0.0055 \\
(0.0052)\end{array}$ & \\
\hline Delinquency Code & $\begin{array}{l}-0.1113^{* * *} \\
(0.0049)\end{array}$ & \\
\hline T x Actionable Code & & $\begin{array}{r}-0.0046 \\
(0.0037)\end{array}$ \\
\hline Actionable Code & & $\begin{array}{l}-0.0280^{* * *} \\
(0.0035)\end{array}$ \\
\hline Control Mean & 0.175 & 0.175 \\
\hline $\mathrm{N}$ & 369,601 & 369,601 \\
\hline
\end{tabular}

Source: Sallie Mae and TransUnion, June 2015 to June 2016.

Outcomes: indicator for having a balance $30+$ days past due in past six months.

All outcomes are first-differences between June 2015 and June 2016.

Delinquency Code is an indicator for having a reason code in June 2015

(the pre-intervention quarter) that mentions a delinquent account.

Actionable Code is an indicator for having a reason code in June 2015

that mentions a direct action a borrower could take to improve her FICO Score.

Robust standard errors in parentheses.

${ }^{*} p<0.10,{ }^{* *} p<0.05,{ }^{* * *} p<0.01$ 
Table 7: Treatment Effects for Main versus Discontinued Sample

\begin{tabular}{lccrr}
\hline & \multicolumn{2}{c}{ FICO Page Views } & \multicolumn{2}{c}{ Financial Outcomes } \\
\cline { 2 - 5 } & March 2016 & March 2017 & Late Pay & FICO \\
& $(1)$ & $(2)$ & $(3)$ & $(4)$ \\
\hline T: Main & $0.0626^{* * *}$ & $0.1082^{* * *}$ & $-0.0051^{* *}$ & $0.5310^{*}$ \\
T: Discontinued & $(0.0016)$ & $(0.0020)$ & $(0.0023)$ & $(0.2768)$ \\
& $0.0633^{* * *}$ & $0.0530^{* * *}$ & -0.0035 & 0.3639 \\
Control Mean & $(0.0025)$ & $(0.0028)$ & $(0.0031)$ & $(0.3802)$ \\
Prob $>\mathrm{F}$ & 0.107 & 0.177 & 0.188 & 676 \\
$\mathrm{~N}$ & 0.733 & 0.000 & 0.503 & 0.568 \\
\hline \hline
\end{tabular}

Source: Sallie Mae, June 2015 to March 2017.

Outcomes: columns $1 \& 2$ are indicators for ever viewing one's page by March 2016 and March 2017, respectively; an indicator for having a balance $30+$ days past due in past six months (column 3) and FICO Score (column 4).

Treatment group members in the discontinued sample received quarterly messages through March 2016 while treatment group members in the main sample received messages for an additional five quarters.

Columns 3 \& 4 are first-differences between June 2015 and March 2017, one year after the discontinued sample stopped receiving treatment messages.

F-statistic test for equality of treatment effects between the two treatment samples.

Robust standard errors in parentheses.

${ }^{*} p<0.10,{ }^{* *} p<0.05,{ }^{* * *} p<0.01$ 
Table 8: Treatment Effects by Experimental Message Type

\begin{tabular}{lcc}
\hline & Late Pay & FICO \\
& $(1)$ & $(2)$ \\
\hline T: Baseline & $-0.0080^{* * *}$ & $0.7177^{* * *}$ \\
& $(0.0023)$ & $(0.2505)$ \\
T: Economic & $-0.0068^{* * *}$ & $0.6122^{* *}$ \\
& $(0.0023)$ & $(0.2512)$ \\
T: Social & $-0.0070^{* * *}$ & $0.6801^{* * *}$ \\
& $(0.0023)$ & $(0.2504)$ \\
\hline Control Mean & 0.175 & 676 \\
Prob $>$ F & 0.757 & 0.849 \\
$\mathrm{~N}$ & 369,601 & 369,601 \\
\hline \hline
\end{tabular}

Source: Sallie Mae and TransUnion, June 2015 to June 2016.

Outcomes: indicator for having a balance $30+$ days past due in past six months (column 1) and FICO Score (column 2).

All outcomes are first-differences between June 2015 and June 2016.

Treatment groups include borrowers who received messages for eight quarters separately by message type (baseline, economic consequences, and social influence messaging).

F-statistic test for equality of treatment effects across the three email messages.

Robust standard errors in parentheses.

${ }^{*} p<0.10,{ }^{* *} p<0.05,{ }^{* * *} p<0.01$ 
Figure 1: Example Sallie Mae FICO Score Page View
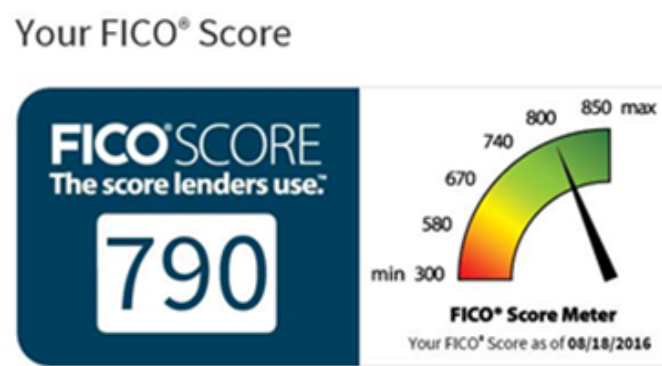

Key Factors affecting your FicO score

1. Length of time revolving accounts have been established

People who do not frequently open new accounts and have longer credit histories generally pose less risk to lenders. in your case, the age of your oidest revolving account and/or the awerage age of your revoting accounts is relatively low.

Keep this in mind: As revolving creda history lengthens and you pay your balts on time, this factor may have less of a negative impact.

2. Proportion of loan balances to loan amounts is too high

Your Fico" score weighs the balances of your mortgage and non-mortgage installment loans (such as auto or student loans) against the original loan amounts. In general. when you first obtain an installment loan your batance is high, and as you pay your loan down, the balance decreases.

Keep this in mind: This factor will have less of a negative impact on your fico"score as you pay down your installment loans and the total balance decreases.

Learn More about your Fico" score

Additional Information

For more information from nco about facos scores and credic, click the links below

Source: Sallie Mae

Figure 2: Example Baseline Email Message

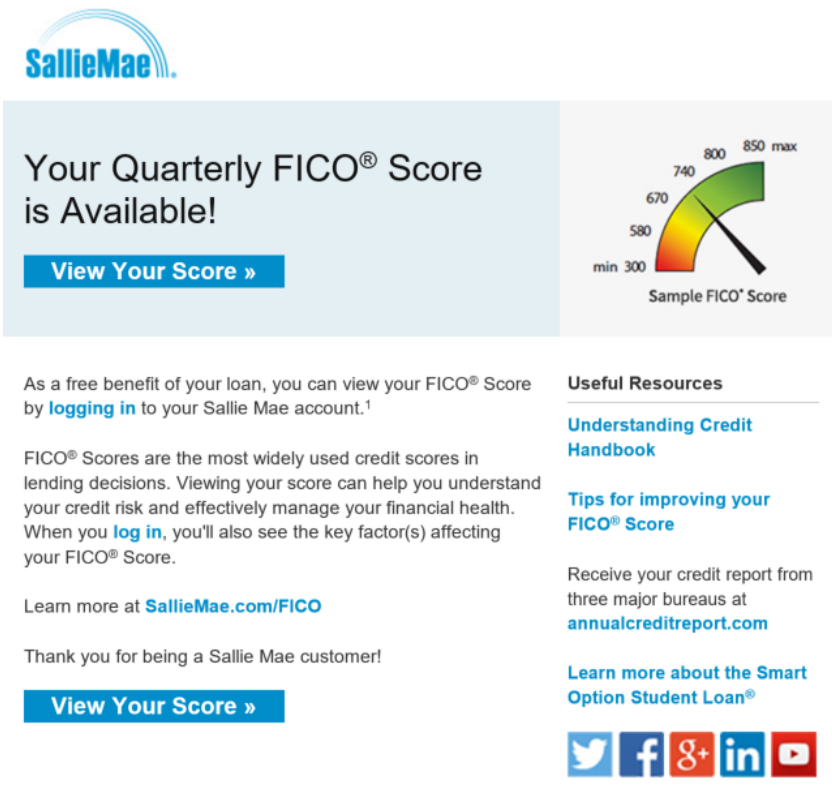

Source: Sallie Mae 
Figure 3: Treatment Email Open Rates

(a) Weekly Open Rate

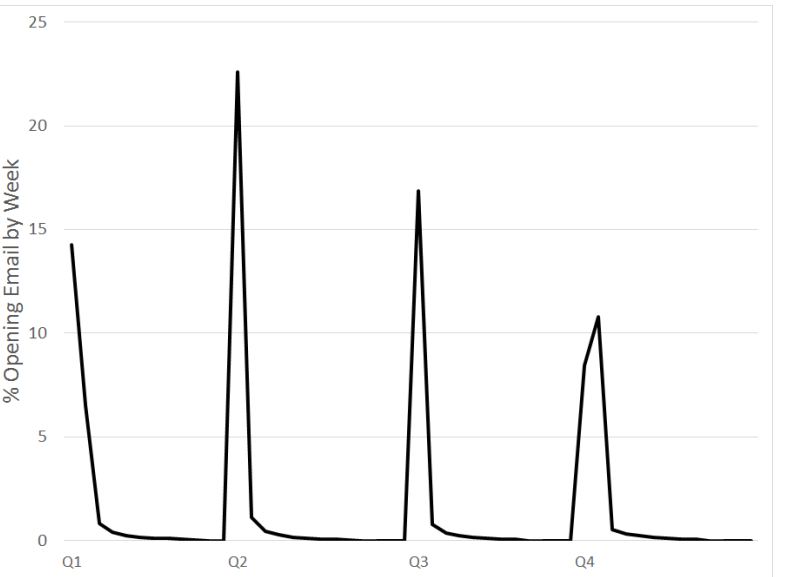

(b) Ever Opened by Week

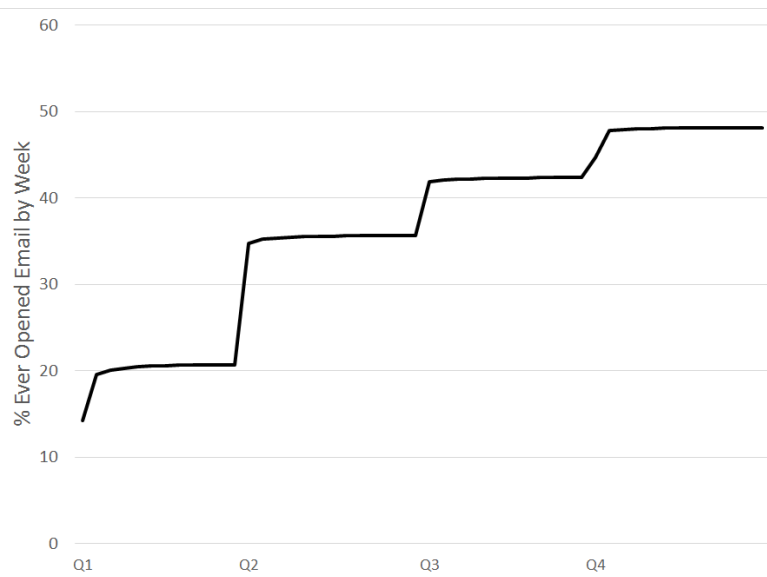

Source: Sallie Mae, June 2015 to June 2016.

Timeline labels correspond to release dates of quarterly communications.

Figure 4: FICO Score Views by Experimental Group

(a) Weekly View Rate

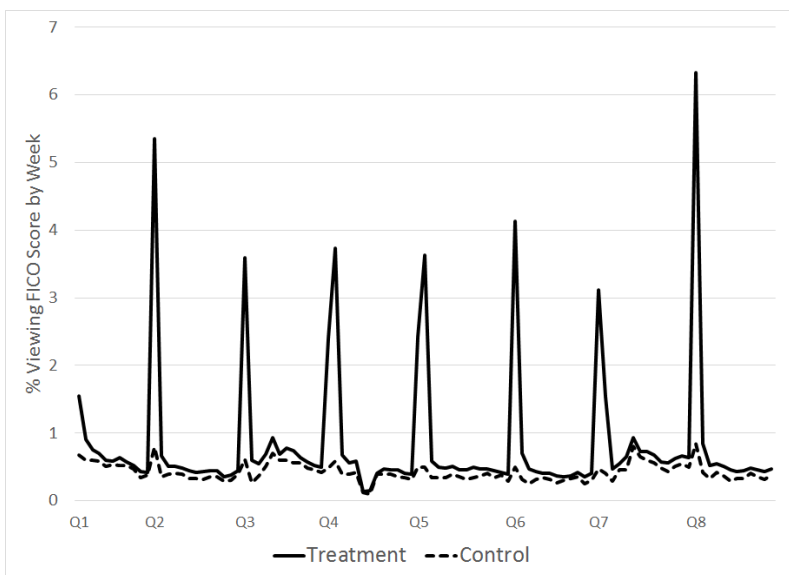

(b) Ever Viewed by Week

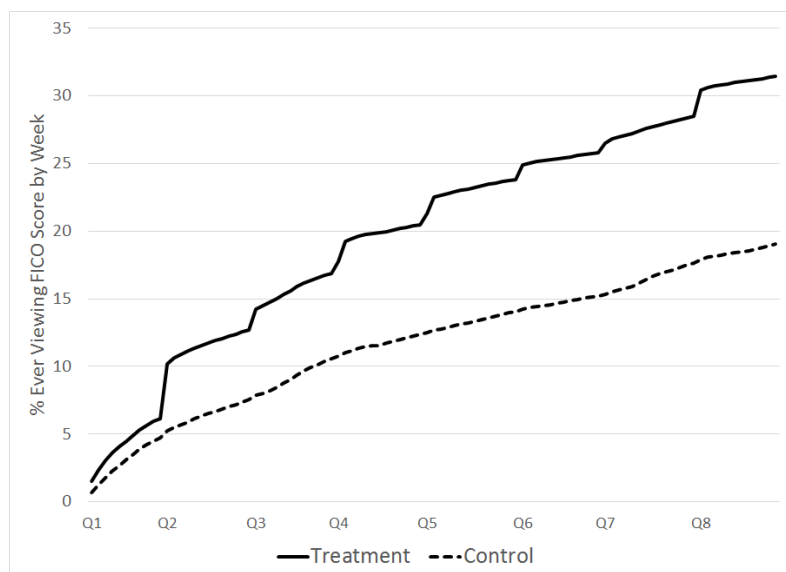

Source: Sallie Mae, June 2015 to June 2017.

Timeline labels correspond to release dates of quarterly communications. 
Figure 5: Treatment Effects by Baseline FICO Score Decile

(a) Late Payments

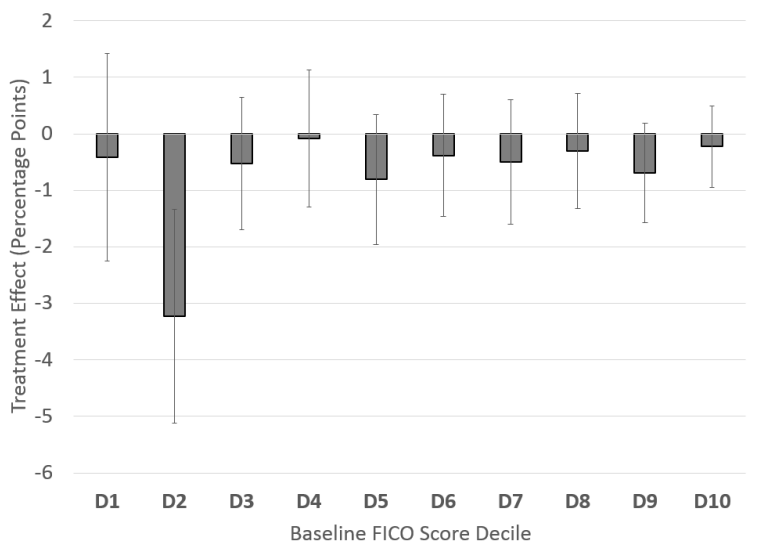

(b) FICO Score

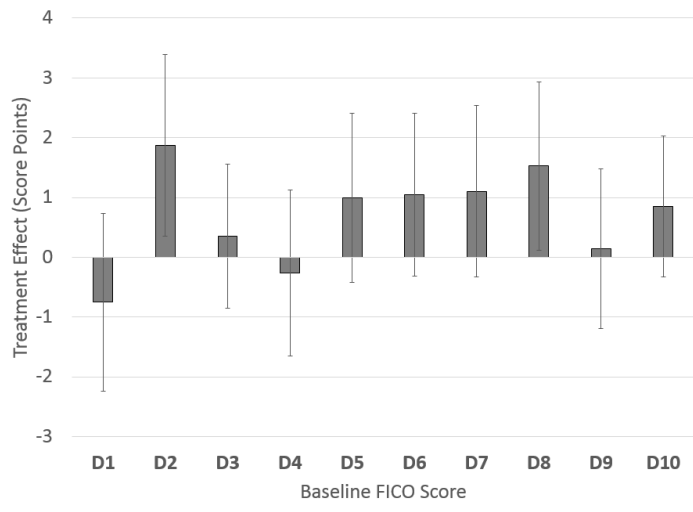

Source: Sallie Mae, June 2015 to June 2016.

Outcomes: indicator for having a balance $30+$ days past due in past six months (Panel A) and FICO Score (Panel B).

All outcomes are first-differences between June 2015 and June 2016.

Figure 6: Treatment Effects by Quarter

(a) Late Payments

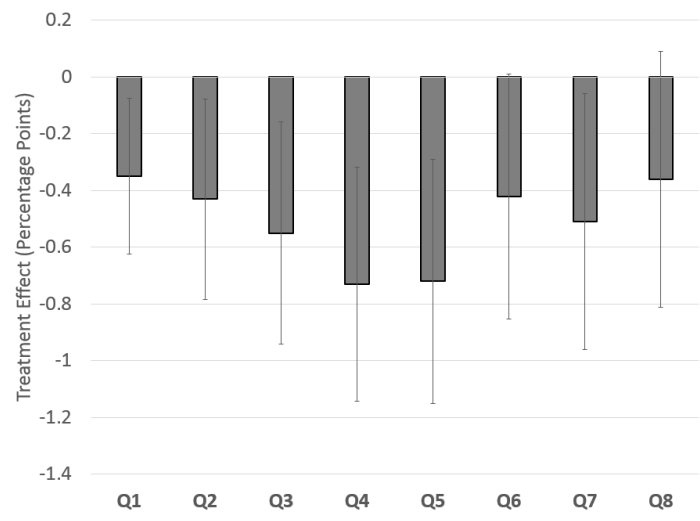

(b) FICO Score

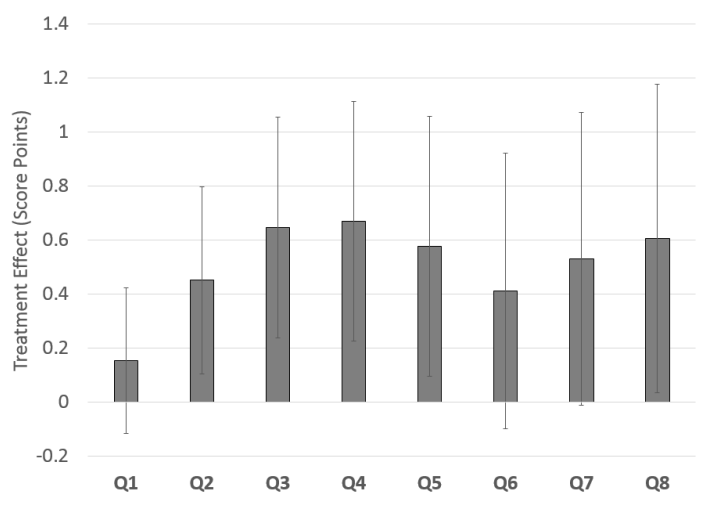

Source: Sallie Mae and TransUnion, June 2015 to June 2017.

Timeline labels correspond to release dates of quarterly communications.

Outcomes: indicator for having a balance $30+$ days past due in past six months (Panel A) and FICO Score (Panel B).

All outcomes are first-differences between June 2015 and the given quarter. 
Figure 7: FICO Score Page Views - Main versus Discontinued Sample

(a) Weekly View Rate

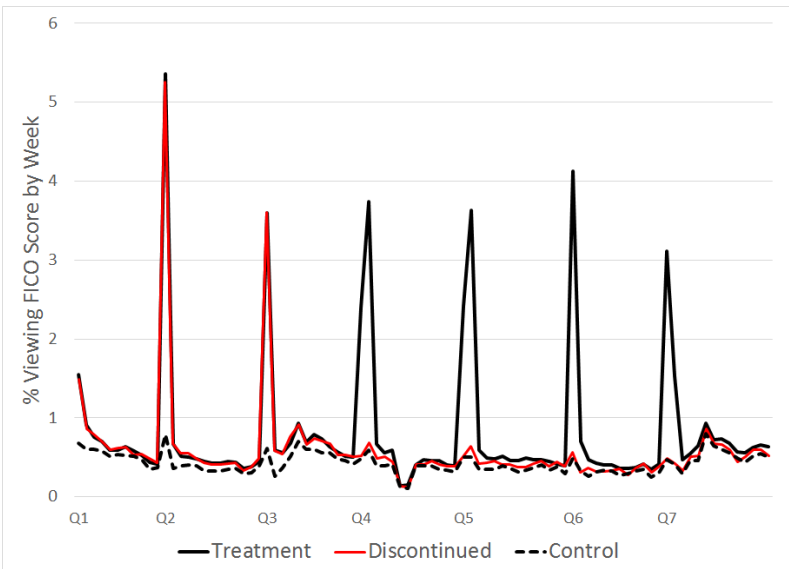

(b) Ever Viewed by Week

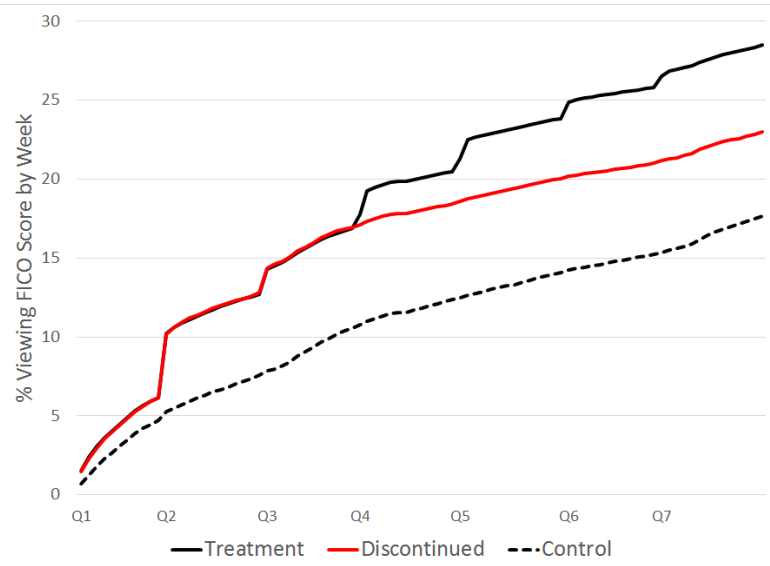

Source: Sallie Mae, June 2015 to March 2017.

Timeline labels correspond to release dates of quarterly communications.

Treatment group members in the main sample received messages for eight quarters; treatment group members in the discontinued sample received messages for three quarters.

Figure 8: FICO Score Page Views by Message Type

(a) Weekly View Rate

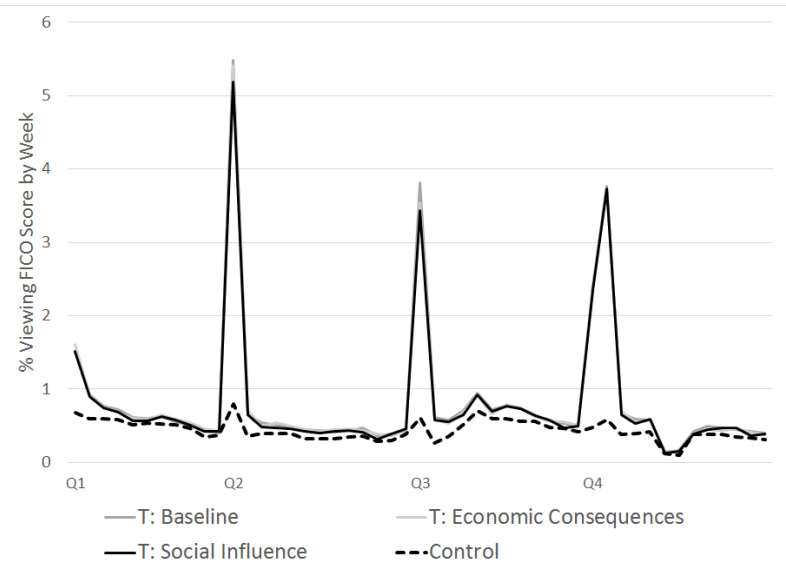

(b) Ever Viewed by Week

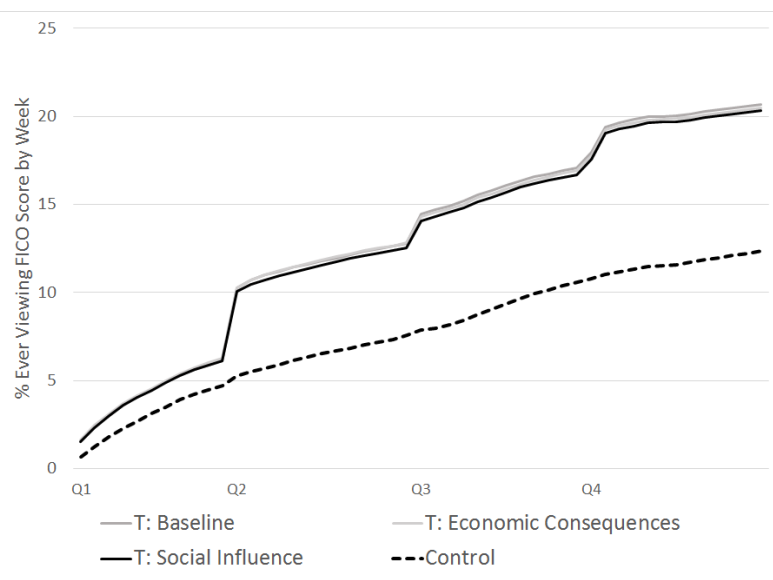

Source: Sallie Mae, June 2015 to June 2017.

Timeline labels correspond to release dates of quarterly communications. 
A Appendix Tables and Figures 
Table A.1: Treatment Status and Demographics by Survey Response

\begin{tabular}{lrrrr}
\hline & $\begin{array}{r}\text { Respondents } \\
(1)\end{array}$ & $\begin{array}{r}\text { Non-Respondents } \\
(2)\end{array}$ & $\begin{array}{r}\text { F-stat } \\
(3)\end{array}$ & $\begin{array}{r}\text { prob>F } \\
(4)\end{array}$ \\
\hline Panel A: Baseline Characteristics & & & \\
Age & 27.1 & 25.2 & 310.20 & 0.00 \\
Out-of-School & 54.0 & 45.0 & 115.72 & 0.00 \\
FICO Score & 696 & 676 & 435.04 & 0.00 \\
\multicolumn{2}{l}{ Panel B: Treatment Status } \\
$\quad$ Treatment Group & 89.0 & & & \\
\hline N & 3,511 & 451,183 & & \\
\hline
\end{tabular}

Source: FICO Financial Literacy Survey, June 2016; TransUnion, June 2015.

Columns $1 \& 2$ report means for respondents and non-respondents of the June 2016 survey, respectively.

Columns $3 \& 4$ report results from the F-test for equality across survey response. 


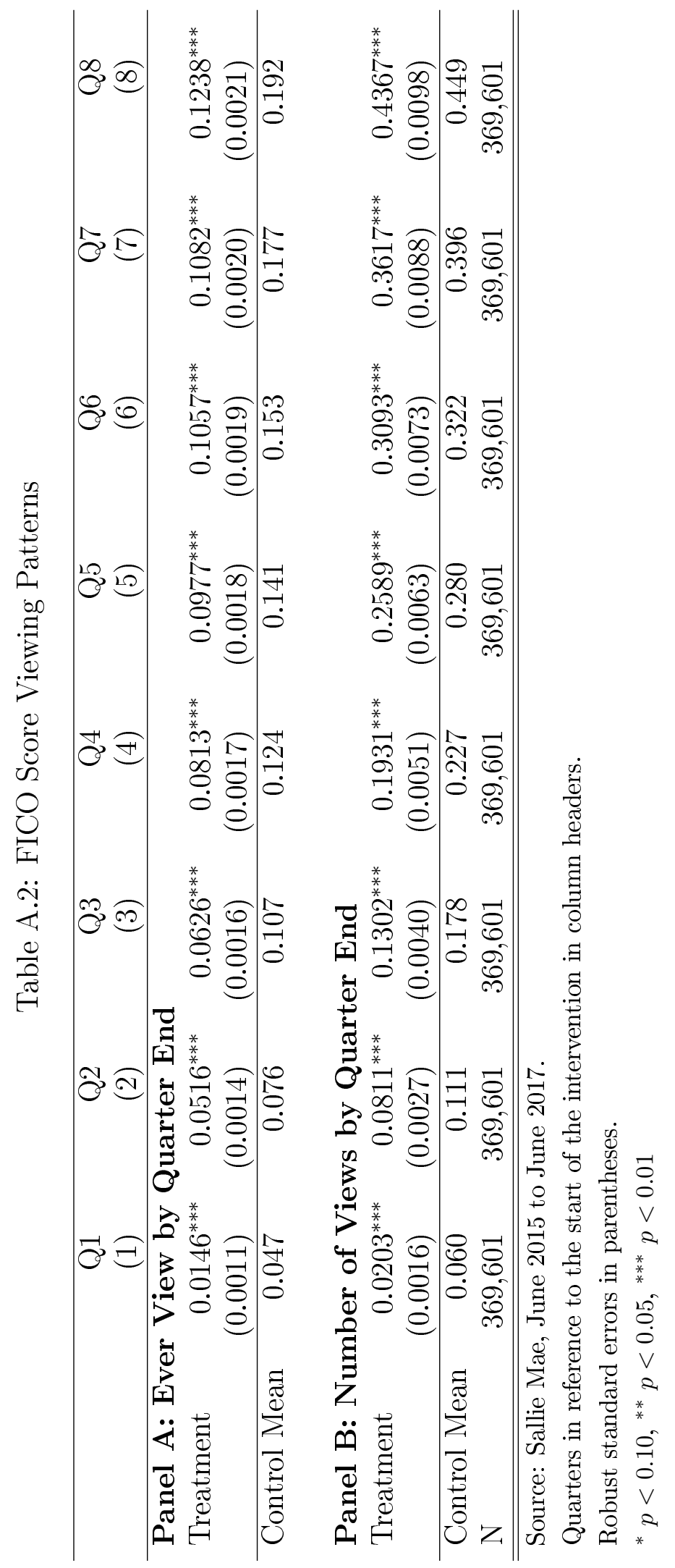


Table A.3: Subgroup Analysis: Age and Student Status

\begin{tabular}{lcccc}
\hline & $\begin{array}{c}\text { Past Due } \\
(2)\end{array}$ & $\begin{array}{c}\text { FICO } \\
(1)\end{array}$ & $\begin{array}{c}\text { Past Due } \\
(2)\end{array}$ & $\begin{array}{c}\text { FICO } \\
(1)\end{array}$ \\
\hline Treatment (T) & $-0.0082^{* *}$ & $0.8227^{* *}$ & $-0.0089^{* *}$ & $0.9691^{* *}$ \\
& $(0.0035)$ & $(0.3423)$ & $(0.0036)$ & $(0.3800)$ \\
T x Below Median Age & 0.0018 & -0.2597 & & \\
& $(0.0043)$ & $(0.4562)$ & & \\
Below Median Age & $0.0185^{* * *}$ & $3.6648^{* * *}$ & & \\
& $(0.0041)$ & $(0.4298)$ & & \\
T x In School & & & 0.0028 & -0.4974 \\
& & & $(0.0044)$ & $(0.4698)$ \\
In School & & & $-0.0043^{* * *}$ & $4.1789^{* * *}$ \\
& & & $(0.0041)$ & $(0.4418)$ \\
\hline Control Mean & 0.175 & 676 & 0.175 & 676 \\
$\mathrm{~N}$ & 369,601 & 369,601 & 369,601 & 369,601 \\
\hline \hline
\end{tabular}

Source: Sallie Mae and TransUnion, June 2015 to June 2016.

Outcomes: indicator for having a balance $30+$ days past due in past six months (column 1 ) and FICO Score (column 2).

"Below Median Age" is an indicator for being 23 years old or under at the start of the intervention.

"In school" is an indicator for being currently in school at the start of the intervention.

All outcomes are first-differences between June 2015 and June 2016.

Robust standard errors in parentheses.

${ }^{*} p<0.10,{ }^{* *} p<0.05,{ }^{* * *} p<0.01$ 


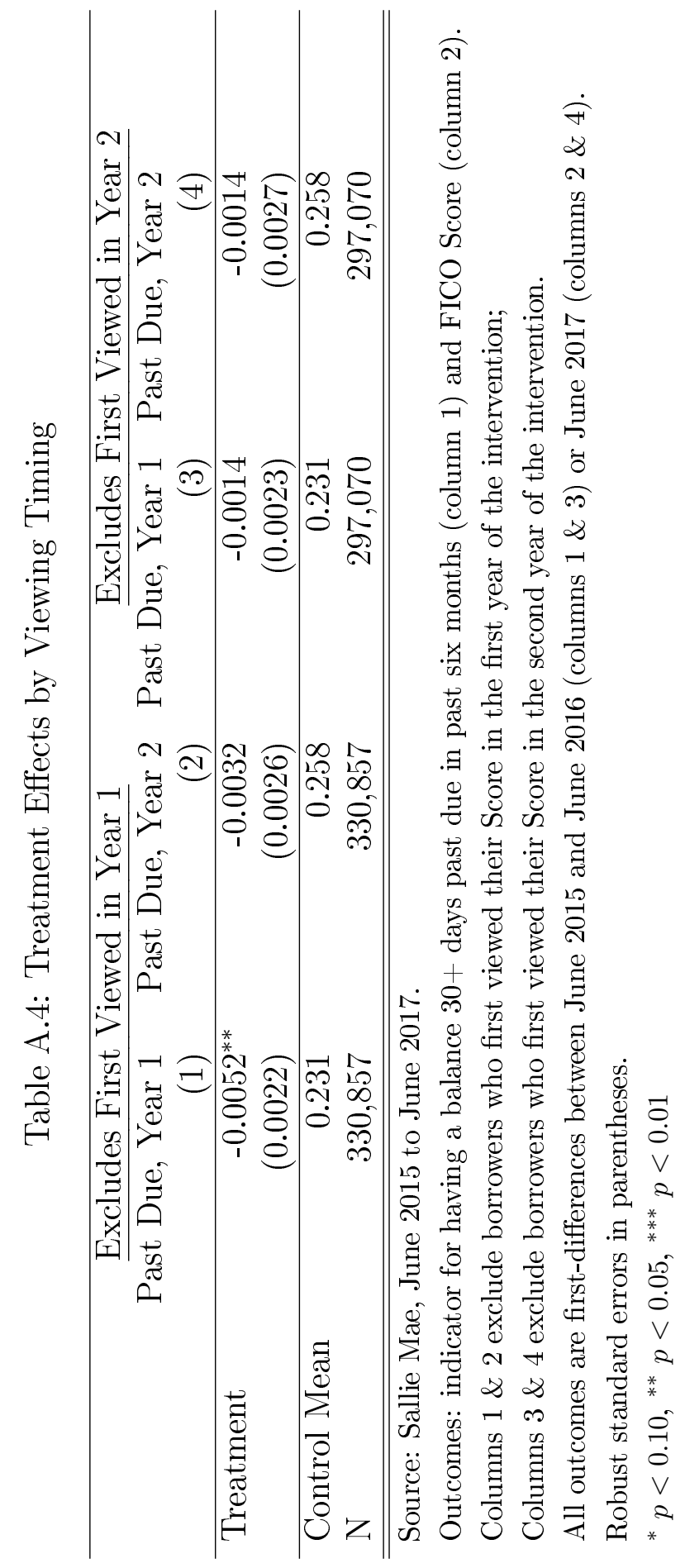




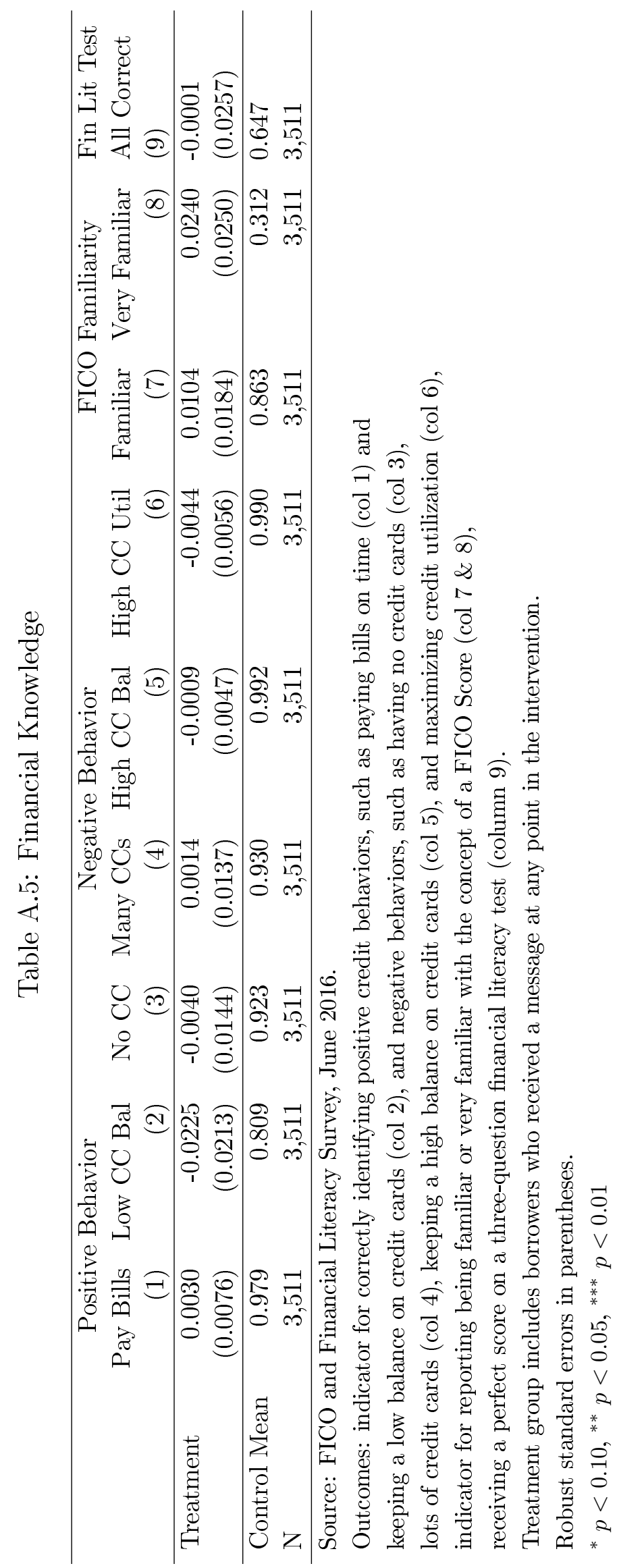


Figure A.1: Components of FICO Score

Components of your $\mathrm{FICO}^{\circledR}$ Score

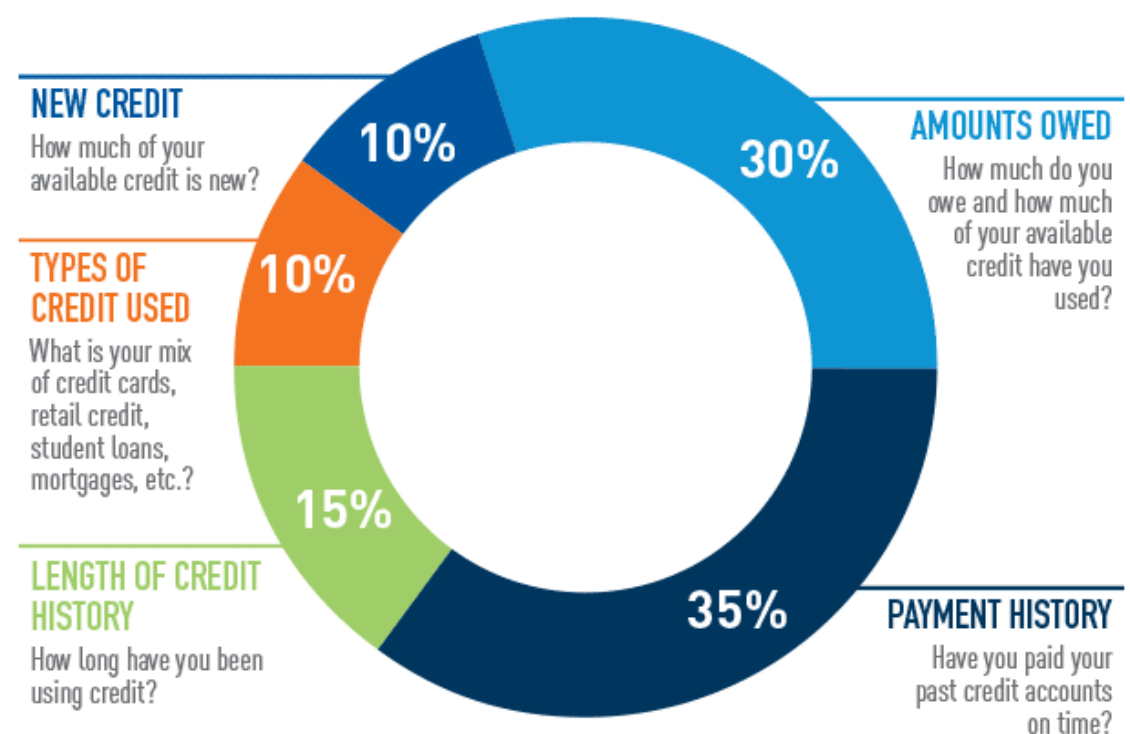

Source: www.myfico.com

Figure A.2: Example of Additional Email Messages

(a) Economic Consequences Message

\section{SallieMaell.}

Your Quarterly FICO ${ }^{\circledR}$ Score is Available!

\section{View Your Score "}

As a free benefit of your loan, you can view your $\mathrm{FICO}^{\circledR} \mathrm{Score}$

by logging in to your Sallie Mae account.

lending decisions. Viewing your score can help you understand your credit risk and effectively manage your tinancial health When you log in, youll also see the key factors) aflecting

Start Today for Better Credit Health Tomorrow How tou manage your student loans today may mpact your FICO Score. Paying student loans on time shows responsite behavior. People Who show responsible payment behavior

When you apply for credit - whether it's a credit card, car Wan, student loan, apartment rental, or mortgage - lenders affect not only a lender's decision hw much credit and on what terms ffor example, the intere te you're offered). Keep in mind that your FICO Score is nly one of the many factors lenders consider when making a credit decision.

Learn more at SallieMae.com/FICO

Thank you for being a Sallie Mae customer

View Your Score »

Source: Sallie Mae (b) Social Influence Message

SallieMaell.

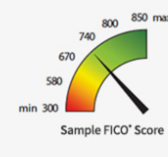

Your Quarterly FICO ${ }^{\circledR}$ Score is Available!

View Your Score "

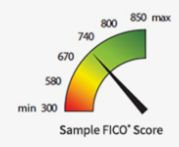

As a free benefit of your loan, you can view your $\mathrm{FlCO}{ }^{\circledR} \mathrm{S}$ core

by logging in to your Sallie Mae account. 1

Useful Resources

Understanding Credit

Tips for improving your

Tips for improving
FICO Score

Receive your credit report from three major bureaus at
annualcreditreport.com

Learn more about the Smant

Learn more about the Sm
Option Student Loan

ت

lending decisions. Viewing your score can help you underst

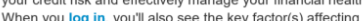
your FICO Score. $^{-}$

Build Your Credit Foundation

A student loan may be your first major credit experience.

Many of your peers are bulding strong financial futures. You

can, too, by effectively managing your student loans.

Leam more at SallieMae.com/FIco

Thank you for being a Sallie Mae customer!

View Your Score » 
Figure A.3: Experiment Timeline

\begin{tabular}{|c|c|c|c|c|c|c|c|c|}
\hline $\begin{array}{l}\text { June } \\
2015\end{array}$ & $\begin{array}{l}\text { Sept } \\
2015\end{array}$ & $\begin{array}{c}\text { Dec } \\
2015\end{array}$ & $\begin{array}{l}\text { Mar } \\
2016\end{array}$ & $\begin{array}{l}\text { June } \\
2016\end{array}$ & $\begin{array}{l}\text { Sept } \\
2016\end{array}$ & $\begin{array}{c}\text { Dec } \\
2016\end{array}$ & $\begin{array}{l}\text { Mar } \\
2017\end{array}$ & $\begin{array}{l}\text { June } \\
2017\end{array}$ \\
\hline $\begin{array}{c}\text { Email conditions } \\
\text { receive message } \\
1,2 \text {, or } 3\end{array}$ & $\begin{array}{l}\text { Email conditions } \\
\text { receive message } \\
\qquad 1,2, \text { or } 3\end{array}$ & $\begin{array}{l}\text { Email conditions } \\
\text { receive message } \\
\qquad 1,2, \text { or } 3\end{array}$ & $\begin{array}{c}\text { All email } \\
\text { conditions } \\
\text { receive message } \\
1 \text { (baseline) }\end{array}$ & $\begin{array}{c}\text { All email } \\
\text { conditions } \\
\text { receive message } \\
1 \text { (baseline) }\end{array}$ & $\begin{array}{c}\text { All email } \\
\text { conditions } \\
\text { receive message } \\
1 \text { (baseline) }\end{array}$ & $\begin{array}{c}\text { All email } \\
\text { conditions } \\
\text { receive message } \\
1 \text { (baseline) }\end{array}$ & $\begin{array}{l}\text { All email } \\
\text { conditions } \\
\text { receive message } \\
1 \text { (baseline) }\end{array}$ & \\
\hline $\begin{array}{c}\text { Control } \\
\text { condition does } \\
\text { not receive } \\
\text { email } \\
\end{array}$ & $\begin{array}{c}\text { Control } \\
\text { condition does } \\
\text { not receive } \\
\text { email } \\
\end{array}$ & $\begin{array}{c}\text { Control } \\
\text { condition does } \\
\text { not receive } \\
\text { email } \\
\end{array}$ & $\begin{array}{c}\text { Control } \\
\text { condition does } \\
\text { not receive } \\
\text { email } \\
\end{array}$ & $\begin{array}{c}\text { Control } \\
\text { condition does } \\
\text { not receive } \\
\text { email } \\
\end{array}$ & $\begin{array}{c}\text { Control } \\
\text { condition does } \\
\text { not receive } \\
\text { email } \\
\end{array}$ & $\begin{array}{c}\text { Control } \\
\text { condition does } \\
\text { not receive } \\
\text { email } \\
\end{array}$ & $\begin{array}{c}\text { Control } \\
\text { condition does } \\
\text { not receive } \\
\text { email }\end{array}$ & \\
\hline $\begin{array}{c}\text { Discontinued } \\
\text { group receives } \\
\text { message } \\
1,2 \text { or } 3 \\
\end{array}$ & $\begin{array}{c}\text { Discontinued } \\
\text { group receives } \\
\text { message } \\
1,2 \text {, or } 3 \\
\end{array}$ & $\begin{array}{c}\text { Discontinued } \\
\text { group receives } \\
\text { message } \\
1,2, \text { or } 3 \\
\end{array}$ & $\begin{array}{l}\text { Discontinued } \\
\text { group does not } \\
\text { receive email }\end{array}$ & $\begin{array}{l}\text { Discontinued } \\
\text { group does not } \\
\text { receive email }\end{array}$ & $\begin{array}{l}\text { Discontinued } \\
\text { group does not } \\
\text { receive email }\end{array}$ & $\begin{array}{l}\text { Discontinued } \\
\text { group does not } \\
\text { receive email }\end{array}$ & $\begin{array}{l}\text { Discontinued } \\
\text { group does not } \\
\text { receive email }\end{array}$ & \\
\hline
\end{tabular}




\section{B FICO Score Views by Source}

As mentioned in Section IV.A, one concern with our administrative data is that it only contains information on FICO Score views through Sallie Mae's website, not through other sources. Therefore, the effects we observe on viewing rates may suggest that the intervention causes borrowers to shift to the lender's website to view their Score rather than through a different source, but does not increase the likelihood of viewing her Score overall. To address this concern, we use data from the FICO financial literacy survey to estimate the effects of the intervention on FICO Score views from any source.

Appendix Table B.1 presents the effects of treatment status on FICO Score views during the first year of the intervention. Column 1 shows the treatment effects on the likelihood of viewing one's FICO Score viewing through any source, not only the provider's website. These effects are consistent with behavior we observed by tracking FICO Score page views in our administrative data. Treatment group members were 8.0 percentage points more likely to have viewed their Score in the first year of the intervention than control group members and the average number of views for this group was 0.3 views higher. These treatment effects are very similar in magnitude to those estimated using administrative data on views at only the provider's website in Table 2 (an increase of 8.1 percentage points in the likelihood of viewing and an increase in the average number of views of 0.2 ). These survey results suggest that the treatment was effective at increasing overall FICO Score views and not simply shifting where individuals viewed their Score. However, it is important to note that the control group means are quite different: only 12 percent of control group members viewed their Score through Sallie Mae's website in the first year of the intervention, while 73 percent of control group members in the survey reported viewing their Score through any source. 
Table B.1: FICO Score Views Through Any Source

\begin{tabular}{lcc}
\hline & Ever Viewed FICO & \# Views \\
& $(1)$ & $(2)$ \\
\hline Treatment $(\mathrm{T})$ & $0.0801^{* * *}$ & $0.2976^{* * *}$ \\
& $0.0236)$ & $(0.1018)$ \\
\hline Control Mean & 3,511 & 2.131 \\
$\mathrm{~N}$ & 3,511 \\
\hline \hline Source: FICO and Financial Literacy Survey, June 2016. \\
Outcomes: indicator for ever viewed FICO Score (column 1) and number of \\
FICO Score views (column 2) through any source in past 12 months. \\
Treatment group includes borrowers who received a message at any \\
point in the intervention. \\
Robust standard errors in parentheses. \\
${ }^{*} p<0.10,{ }^{* *} p<0.05,{ }^{* * *} p<0.01$
\end{tabular}

\section{FICO and Financial Literacy Survey}

\section{A. FICO Score Views}

Q: How many times have you viewed your FICO Score within the past 12 months?

(1) I did not review my FICO@ Score within the past 12 months

(2) 1 time

(3) 2 times

(4) 3 times

(5) 4 times

(6) 5 or more times

(7) Not sure

\section{B. Personal FICO Score Knowledge}

Q: Do you know what your FICO Score is?

(1) Between 0 and 299

(2) $300-449$

(3) $450-549$ 
(4) $550-649$

(5) $650-749$

(6) $750-850$

(7) More than 850

(8) No - I don't know what my FICO Score is

(9) No - I don't have a FICO Score

(10) No - I don't know what a FICO Score is

\section{Knowledge of Creditworthy Actions}

Q: Which of the following do you think are considered positive credit behaviors - that is actions that may improve your credit? (Select all that apply)

(1) Paying your bills on time

(2) Having no credit cards

(3) Having a lot of credit cards

(4) Keeping a high balance on your credit card

(5) Keeping a low balance on your credit card

(6) Using as much of your credit limit as possible

(7) None of the above

\section{FICO Familiarity}

Q: How familiar are you with the concept of a FICO Score or another credit score?

(1) Very familiar - I'm confident that I can explain what a credit score is to a friend

(2) Somewhat familiar - I could explain what a credit score is in very general terms

(3) Somewhat unfamiliar - I have heard about credit scores, but I don't exactly know what a credit score is

(4) Not at all familiar - I have never heard of credit scores 


\section{E. Financial Literacy}

Q1. If a student takes out a $\$ 5,000$ student loan at $7 \%$ interest, will he have to pay back...?

(1) Less than $\$ 5,000$

(2) Exactly $\$ 5,000$

(3) More than $\$ 5,000$

(4) I'm not sure

Q2. Imagine that there are two options when it comes to paying back your student loan and both come with the same interest rate. Provided you have the needed funds, which option would you select to minimize your out-of-pocket costs over the life of the loan?

(1) Option 1 allows you to take 10 years to pay back the loan

(2) Option 2 allows you to take 20 years to pay back the loan

(3) Both options have the same out-of-pocket cost over the life of the loan

(4) I'm not sure

Q3. When a private student loan, such as the Smart Option Student Loan from Sallie Mae, is deferred, that is, no payment is required while the student is enrolled in college, what happens to the interest on this loan?

(1) Interest doesn't start accruing until the student has graduated and starts repaying the loan

(2) Interest is capitalized, that is, the interest that accrues during the deferment period is added to the principal amount of the loan

(3) Interest accrues, but nobody has to pay for it

(4) Other, please specify

(5) I don't know 